\title{
Article \\ Sensitivity Analysis of the Global Response of Flexible Rockfall Barriers
}

\author{
Cyril Douthe *(1), Chloé Girardon and Romain Boulaud
}

Citation: Douthe, C.; Girardon, C.; Boulaud, R. Sensitivity Analysis of the Global Response of Flexible Rockfall Barriers. Geosciences 2022, 12

75. https://doi.org/10.3390/ geosciences12020075

Academic Editors: Didier Hantz, Salvatore Grasso and Jesus Martinez-Frias

Received: 4 November 2021

Accepted: 27 January 2022

Published: 6 February 2022

Publisher's Note: MDPI stays neutral with regard to jurisdictional claims in published maps and institutional affiliations.

Copyright: (c) 2022 by the authors. Licensee MDPI, Basel, Switzerland. This article is an open access article distributed under the terms and conditions of the Creative Commons Attribution (CC BY) license (https:// creativecommons.org/licenses/by/ $4.0 /)$.

\author{
Laboratoire Navier, École des Ponts ParisTech, University Gustave Eiffel, CNRS, 6 \& 8 Avenue Blaise Pascal, \\ 77420 Champs sur Marne, France; chloe.girardon@eleves.enpc.fr (C.G.); \\ romain.boulaud@developement-durable.gouv.fr (R.B.) \\ * Correspondence: cyril.douthe@univ-eiffel.fr; Tel.: +33-16415-3740
}

\begin{abstract}
Protection barriers against the fall of boulders and rocks are structures with non-linear mechanical behaviour that make the study particularly complex. In this study, the understanding of an experimentally observed variability was investigated numerically using a non-linear spring-mass equivalence. First, key figures of the experiments on which this study is based are detailed. Then, the numerical model for the dynamic simulation of the barrier deformation under impact is presented. Finally, the variability due to block-related parameters and then net-related parameters are explored and evidence the role of the cables' geometric stiffness in the global response of the fence.
\end{abstract}

Keywords: rockfall barrier; structural engineering; brake activation threshold; geometric stiffness

\section{Introduction}

The risk due to falling rocks and boulders is all the greater because it is difficult to predict it as well as to anticipate the trajectory or energy of the block [1]. Passive protections must therefore be designed to be able to stop the fall of blocks alongside more or less large areas of instability. These protections often take the form of nets supported by edge cables and posts attached to the cliff [2].

Mechanical understanding of these rockfall protections is difficult: non-linear and dynamic behaviours, in a context of large displacements and irreversible mechanisms to dissipate energy, make the study of these barriers all the more complex. A series of test campaigns were conducted: by rolling rocks along the slope (Muraishi et al. [3], McCauley et al. [4]), by moving them along a cable (Peila et al. [5], who proposed semi-empirical design methods based on their measurements of the maximum deceleration), or launching them vertically (Gerber et al. [6] and Muraishi and Sano [7]), in addition to the experiments of Grassl et al. [8] in partnership with the Swiss company Geobrugg. Experimental tests for a better understanding at the net scale were conducted by Trad [9] and Bertrand et al. [10].

Some of these experiments may be realistic but cannot be controllable and thus are difficult to repeat. Others are well repeatable, but the rotating component of the speed is missing. Therefore, a standardisation of experimental test protocols was carried out (ETAG [11]), which set out a 1:1 test protocol and a series of results to be achieved in order to validate a barrier and allow its commercialisation in the European Union. Impacts were defined by their kinetic energy $E_{c}$. A MEL impact ("Maximum Energy Level") corresponds to an energy $E_{c}$; a SEL impact ("Service Energy Level") corresponds to two successive energy impacts of $E_{c} / 3$. These two types of impact are centred in the central module of the barrier. The ETAG standard also defines the shape of the module and requires an impact velocity of at least $25 \mathrm{~m} / \mathrm{s}$. A review of approval of flexible rockfall protection systems was recently provided by Volkwein et al. [12] and outlined some general features on the response of such structures over a large variety of kits.

This barrier validation protocol leads to a questioning of its representativeness under more general conditions-without a safety coefficient, external elements are not taken into 
account, as well as the possibility of non-central impacts (Toe et al. [13]). In addition, these validation experiments are very expensive; a realistic numerical study is therefore useful to ensure the feasibility of the experiment. A number of models have been presented in the literature. The following list is non-exhaustive. Rockfall barrier models have been developed by Nicot et al. [14], where ASM rings are modelled by a node that is located at its centre. The interaction between the rings is modelled by imaginary bars joining all the rings. Volkwein [15] suggests a four-node mechanical model of ring. It is made of two parts: two diagonal tension-only springs and one circumferential spring. A recent publication by Boulaud and Douthe [16] has however shown that the modelling choice for the net had little influence on the global response of the structure, which was mainly governed by the architecture of the barrier and the supporting cable behaviour. Non-standard studies have also been carried out, by Hambleton et al. [17] about the perforation of the net by the block or by Coulibaly et al. [18] on variability on the curtain effect or consecutive impacts.

In this article, a brief synthesis of the experimental results on which the present study is based will be presented first and complement some aspects of the results published in [19]. Then, the numerical model in the form of a non-linear spring-mass system will be introduced. Afterwards, a statistical analysis of the results will be carried out according to a parameter related to the boulder: its impact position. Next, a sensitivity analysis will be conducted using parameters related to the barrier: the prestress in the edge cables, as well as the brake threshold. A discussion on the order of magnitude of variations induced by the different parameters will conclude the article.

\section{Presentation of the Experimental Set-Up}

The present study was partly supported by the C2ROP programme (https:/ / www.c2 rop.fr/, accessed on 4 February 2022), a French national project that seeks both to bring together stakeholders in the field of rockfall risks and to create a platform of operational resources, in particular through two experimental campaigns carried out in 2016 and 2019, which are abundantly detailed in Olmedo, I et al. [19]. The experimental analyses conducted here are based on the data collected from these campaigns, which consist of 1:1 scale tests of block drops on a rockfall barrier described below (see set-up photo in Figure 1).

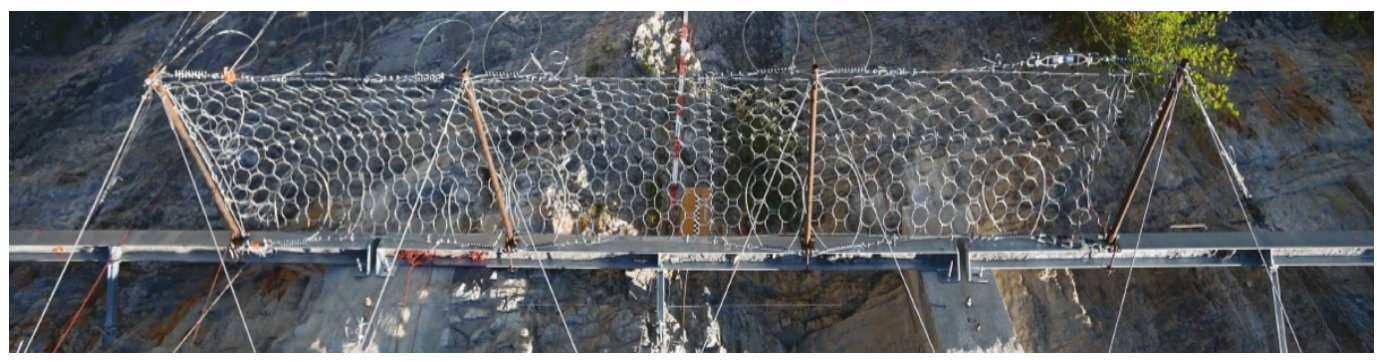

Figure 1. Top view of the experimental set-up (by courtesy of the NGE Foundation).

\subsection{Rockfall Barrier Architecture}

The protective barrier used in the tests and numerical simulations is made up of three modules $(2.75 \mathrm{~m} \times 5.00 \mathrm{~m}$ each $)$ anchored perpendicular to the cliff. The size of the net is $2.75 \mathrm{~m}$ high (direction $y$ in the following Figure 4) and $15.0 \mathrm{~m}$ long (direction $x$ below). This barrier consists of a net formed by intertwined anti-submarine rings (ASM4 made of rings with a diameter of $275 \mathrm{~mm}$ and strand of $7.5 \mathrm{~mm}$ ), as well as ten edging cables $(12 \mathrm{~mm}$ ) - four on each side parallel to the cliff (cables 1,5,6, and 8 at the base of the posts and cables 2, 3, 4, and 7 at the top of the posts) and one on each lateral edge (cables 9 and 10). The entire structure, which consists of the cables and the net, is anchored to the cliff by means of four steel posts, each head of which is held by struts anchored to the cliff. The geometry of the barrier is shown on Figure 2. 


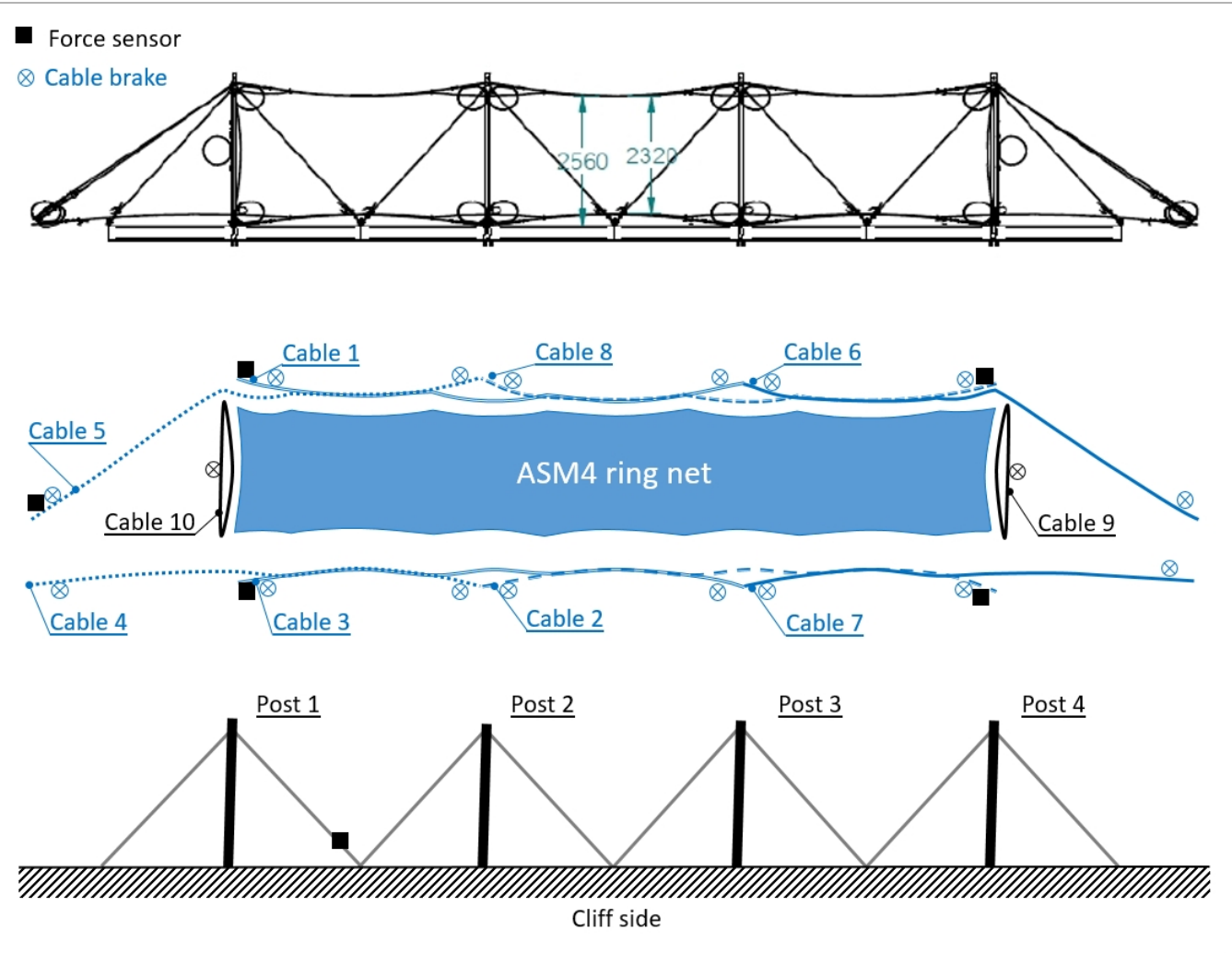

Figure 2. Architecture of the experimental flexible-barrier. Top: Technical drawing from above of the barrier by courtesy of the NGE Foundation. Middle: Decomposition of the supporting cable and of their weaving with the ASM4 ring net. The circle at the cables end represent the brakes ("snake" brake provided by the NGE Foundation), and the black square represents the force sensors. Bottom: Supporting structures made of post and struts.

The upstream and downstream sides are symmetrical for the edge cables. The outer cables $(4,5,6$, and 7 in Figure 2) connect the lateral anchor to the head of the central post. The central cables ( 1 and 3 in Figure 2 ) connect the heads of the first and third post. In the neighbourhood of the second post, the net is thus linked only to cables 1 and 3 , so that when the net is impacted it can deform softly around the post avoiding the stress concentration in the net. Symmetrically, cables 2 and 8 run from the second post to the fourth post, without touching directly the third post. Each cable is hence partially connected to the net and free at the pole heads. Thus, with this assembly, the net is held by two cables in its module centres and by one cable near to the posts.

The barrier works as follows: a block is intercepted by the net, which deforms. The net slides along the edge cables (Boulaud et al. [20]), which deform. When the stress in these cables reaches a threshold force $F_{s}$, friction brakes (called a "snake brake" by the provider NGE Foundation - they are shown in Figure 3) activate. In practice, the stress in the edge cables is not uniform, and one cannot foresee which end will be the most solicited. Therefore, one brake is set at each end for all the cables, except the lateral cables 9 and 10, which form a closed loop and require thus only one brake. The block stops finally when all the kinetic energy is dissipated. 


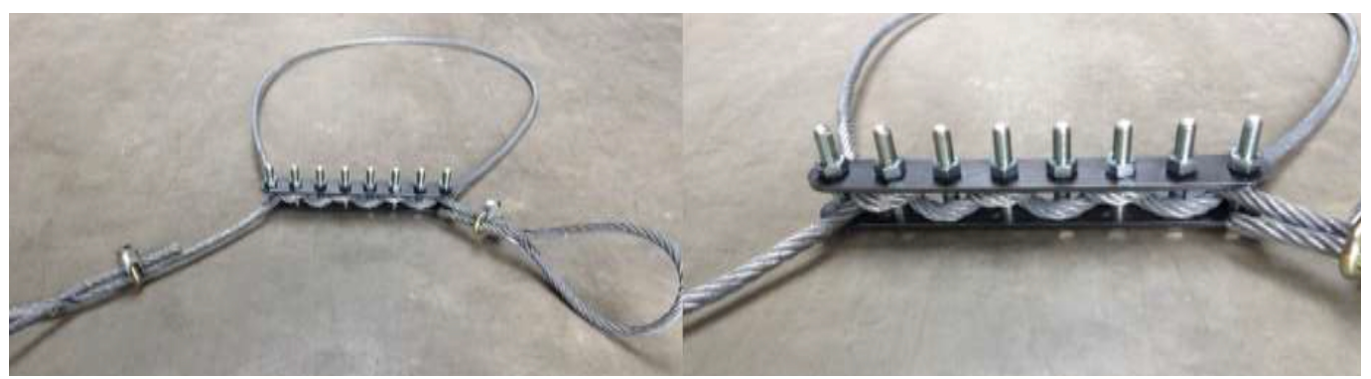

Figure 3. Image of the snake brake provided by the NGE Foundation: it is made of two steel plates connected by a series of bolts through which a cable is braided at both ends of the loop (by courtesy of the NGE Foundation).

\subsection{Measuring Devices}

For each test of the two campaigns, a number of force sensors were attached to the cables between the brake and the anchor (each sensor corresponds to a canal indicated in Figure 2). All the central cables (labelled 4, 5, 6, and 7 in Figure 2) were hence monitored, plus one strut between the cliff and the head of the second posts (see Figure 2). The acceleration of the block was recorded by an accelerometer within the block. After impact, the residual height and the final brake elongation were measured on the deformed structure.

Then, each block fall was filmed with high-speed cameras: one with a top view and one with frontal view. When the quality of the video allowed it, digital image correlation (DIC) could be used to retrieve the block position through time as well as the brake elongations as a function of time. This manual operation introduced some intrinsic variability, which was quantified performing the same measurement four times for four different videos. The resulting relative deviation of the maximum block displacement was $4.5 \%$, which seems acceptable considering the variability in the other variables.

\subsection{First Campaign}

The first set of tests during this campaign consisted of two impacts centred on the net, with the same impact energy $E_{M E L}=270 \mathrm{~kJ}$. For the second set of tests, three consecutive impacts (with the removal of the block from the net before the next impact) occurred, with an impact energy for each of $E_{S E L}=90 \mathrm{~kJ}$, i.e., a third of $E_{M E L}$. The structure was not repaired between the three impacts.

The main objectives of this campaign were first to investigate the reproducibility of experimental results and second to investigate the hypothesis that the effect of successive impacts compared with the effect of one impact with an energy equal to the sum of successive impacts ( $3 S E L \equiv M E L$ ?).

\subsection{Second Campaign}

During the second test campaign, five different impacts took place (the first one on an isolated module and the other four on the complete barrier):

1. An impact centred on a structure composed of a single net instead of three, with an impact energy $E_{1}=270 \mathrm{~kJ}$ (individual module).

2. A centred impact with a pre-loaded net, with an impact energy $E_{2}=270 \mathrm{~kJ}$ (pre-loaded impact).

3. A slightly off-centre impact, with an impact energy $E_{3}=270 \mathrm{~kJ}$ (off-centred impact).

4. An impact on a side net, with an impact energy $E_{4}=270 \mathrm{~kJ}$ (lateral impact).

5. An impact centred in the central module following a first impact in the lateral module, with an impact energy $E_{5}=90 \mathrm{~kJ}$ (consecutive impacts).

The location of these impacts are reported in Figure 4. The main objective of this second campaign was to investigate if the impact conditions of the standard were unfavourable when compared to other more realistic impact conditions. 


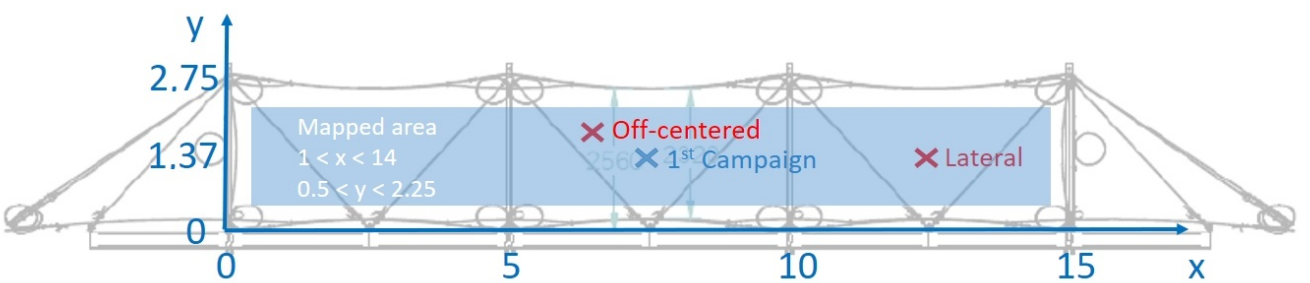

Figure 4. Location of impacts in the two experimental campaign, as well as zone mapped by the numerical simulations (a margin of $0.5 \mathrm{~m}$ (resp. $1 \mathrm{~m}$ ) was taken along the long edges (resp. lateral edges) to avoid direct interaction of the block with edge cables).

\section{Main Results of the Experimental Campaigns}

\subsection{First Campaign}

The results of the first campaign are synthesised in the Table 1 below.

Table 1. Characteristics recorded for each of the two MEL and three SEL impacts-first campaign.

\begin{tabular}{lllllll}
\hline Test & MEL 1 & MEL 2 & SEL 1 & SEL 2 & SEL 3 & SEL $_{\text {tot }}$ \\
\hline Theor. energy & $270 \mathrm{~kJ}$ & $270 \mathrm{~kJ}$ & $90 \mathrm{~kJ}$ & $90 \mathrm{~kJ}$ & $90 \mathrm{~kJ}$ & $3 \times 90 \mathrm{~kJ}$ \\
\hline $\begin{array}{l}\text { Total brake elong. } \\
\text { (eq. energy 25 kN ) }\end{array}$ & $828 \mathrm{~cm}$ & $1136 \mathrm{~cm}$ & $348 \mathrm{~cm}$ & $288 \mathrm{~cm}$ & $256 \mathrm{~cm}$ & $892 \mathrm{~cm}$ \\
\hline Maximal displacement & $4.44 \mathrm{~m}$ & $5.05 \mathrm{~m}$ & & & $(64 \mathrm{~kJ})$ & $(223 \mathrm{~kJ})$ \\
\hline Residual height & $1.4 \mathrm{~m}$ & $1.2 \mathrm{~m}$ & $1.5 \mathrm{~m}$ & $1.1 \mathrm{~m}$ & $0.9 \mathrm{~m}$ & \\
\hline
\end{tabular}

It was observed that the resulting data differed significantly for the two MEL tests: there was a 13 percent difference between the two maximum displacements reached by the block, as well as a 31 percent difference in the total brake elongation. Considering that the brake threshold was constant and equal to $25 \mathrm{kN}$ (as specified by the manufacturer), this difference in the brake elongation can be interpreted in terms of energy dissipated by the brakes. Following this reasoning for MEL 2, this equivalent energy was higher than the impacting energy, which is not possible and indicates that the average threshold values must have been lower than $25 \mathrm{kN}$ in this case.

Considering then the three successive SEL tests, it appears that the energy dissipated by each test diminished progressively with the number of tests. This can be easily understood by the fact that, test after test, the geometry of the fence changed and became more efficient to resist vertical forces. Indeed, while the net deformed, the edge cables inclined so that consequently the vertical component of the forces in the edge cables, which is given by the brake threshold, increased. If the vertical component of the cable forces increases, the vertical reaction on the block increases as does the kinetic energy dissipated for a given elongation. Therefore, the additional brake elongation (or energy dissipated by the brakes) diminishes with each impact increment. Notice that the total energy dissipated by the three SEL test was comparable to MEL 1 and MEL 2. This confirms the idea that what drives the barrier response is the impacting energy.

\subsection{Second Campaign}

Table 2 then shows the results of the second campaign. It was observed that the impact characteristics vary greatly from one test to another: a twofold variation in the total brake elongation and a maximum block displacement variation of nearly $40 \%$.

This variability may depend on many factors. Non-exhaustively, one can mention the location of the impact of the block, the pre-stress in the edge cables, or the uncertainty on the effective brake-activation threshold. Yet, force sensors had been installed on the main cables during the tests, and pre-stress measurement had been conducted before the impact. 
Before conducting the sensitivity analysis, experimental data on these two characteristics are presented.

Table 2. Characteristics recorded for each of the five test impacts for the second campaign.

\begin{tabular}{llllll}
\hline Test & $\begin{array}{l}\text { Indiv. } \\
\text { Module }\end{array}$ & Pre-Loaded & $\begin{array}{l}\text { Off- } \\
\text { Centred }\end{array}$ & Lateral & Consecutive \\
\hline Location & $\begin{array}{l}x=7.5 \mathrm{~m} \\
y=1.37 \mathrm{~m}\end{array}$ & $\begin{array}{l}x=7.5 \mathrm{~m} \\
y=1.37 \mathrm{~m}\end{array}$ & $\begin{array}{l}x=6.1 \mathrm{~m} \\
y=1.8 \mathrm{~m}\end{array}$ & $\begin{array}{l}x=13.4 \mathrm{~m} \\
y=1.37 \mathrm{~m}\end{array}$ & $\begin{array}{l}x=7.5 \mathrm{~m} \\
y=1.37 \mathrm{~m}\end{array}$ \\
\hline Total brake elong. & $581 \mathrm{~cm}$ & $579 \mathrm{~cm}$ & $1210 \mathrm{~cm}$ & $474 \mathrm{~cm}$ & $670 \mathrm{~cm}$ \\
$($ eq. energy $25 \mathrm{kN})$ & $(145 \mathrm{~kJ})$ & $(145 \mathrm{~kJ})$ & $(303 \mathrm{~kJ})$ & $(119 \mathrm{~kJ})$ & $(168 \mathrm{~kJ})$ \\
\hline Max. displ & $4.74 \mathrm{~m}$ & $4.19 \mathrm{~m}$ & $5.08 \mathrm{~m}$ & $4.18 \mathrm{~m}$ & $3.48 \mathrm{~m}$ \\
\hline Res. height & $1.36 \mathrm{~m}$ & no data & $1.01 \mathrm{~m}$ & $0.94 \mathrm{~m}$ & no data \\
\hline
\end{tabular}

\subsection{Analysis of the Prestress Distribrution in the Cables}

The ring net and their supporting cables have no bending rigidity. Therefore, to resist the gravity load, they need to be prestressed during the set-up of the fence in order to build a quasi-horizontal barrier perpendicular to the cliff. The curvature of the edge cables (which can be seen in Figure 2 for example) is directly associated with the ratio between the distributed gravity load induced by the ring net and the prestress in the cable. The level of this prestress is relatively low for two reasons: first, to be easily set by workers and, second, to allow the highest possible margin with brake thresholds.

During these two test campaigns, 47 prestress values were thus measured thanks to an arbalest with an accuracy of $\pm 2 \%$ [21]. To establish a distribution law for the prestress, it is necessary to ensure independence between values. However, the barrier consists in an hyperstatic structure, with a relatively high level of hyperstaticity: when one pulls on one cable, the tensions in the others vary. It is therefore preferable to take the pre-stress values for each cable individually from each test (these values are indeed independent), to identify for each cable the distribution law characteristics (through the various experiments). Then, from the identified prestress distributions, one can determine an average distribution law, which is shown in Figure 5 with the characteristics displayed in Table 3.

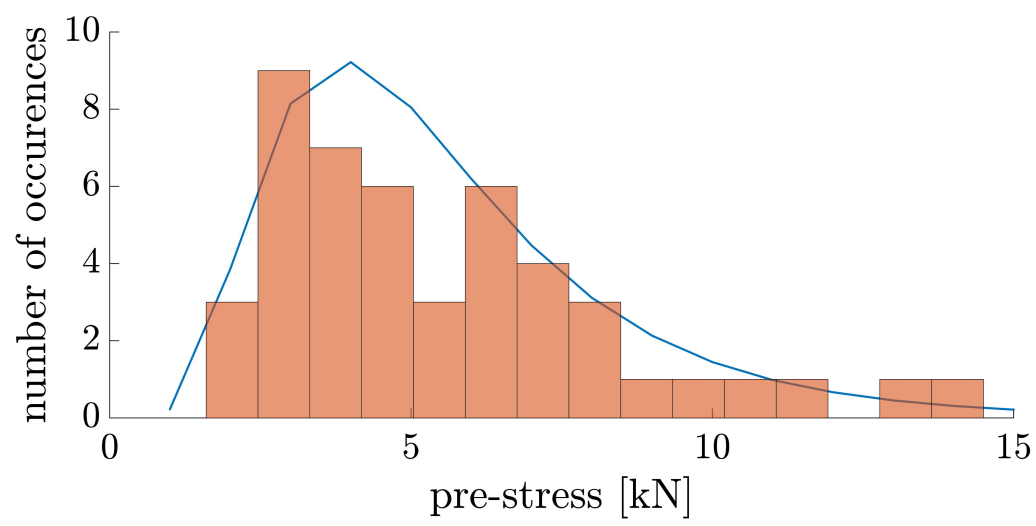

Figure 5. Distribution of experimentally measured prestressing forces in all the cables.

Table 3. Pre-loading distributions.

\begin{tabular}{ccc}
\hline Standard Deviation & Average & Expected Value \\
\hline $3.0 \mathrm{kN}$ & $6.2 \mathrm{kN}$ & $5.6 \mathrm{kN}$ \\
\hline
\end{tabular}


A log-normal distribution of parameters $\mu=1.60$ and $\sigma^{2}=0.25$ is defined $(x>0)$ :

$$
f_{X}(x ; \mu, \sigma)=\frac{1}{x \sigma \sqrt{2 \pi}} \cdot \exp \left(-\frac{(\ln x-\mu)^{2}}{2 \sigma^{2}}\right)
$$

The average value of this distribution was $6.2 \mathrm{kN}$, which is slightly higher than the value obtained by direct averaging of the recorded data, which was of $5.6 \mathrm{kN}$. The standard deviation was about $3.0 \mathrm{kN}$.

\subsection{Analysis of Brake-Activation Threshold Distribution}

In the same way, during these two campaigns, 27 usable brake-activation threshold values were identified. The force values were obtained directly from the force sensor data whose location is indicated in Figure 2. To obtain the complete force/displacement curve, digital image correlation was used to measure the distance between brake anchor points on images from the high-speed camera. The time correlation was made manually by combining the force/time curve and the elongation/time curve. Usable data of the brake threshold were then found when data were available from three sources: data from the force sensor, visibility of the brake on the high-speed camera images, and data of the prestressing force. Four typical force-displacement diagrams are displayed in Figure 6. These values are all independent.
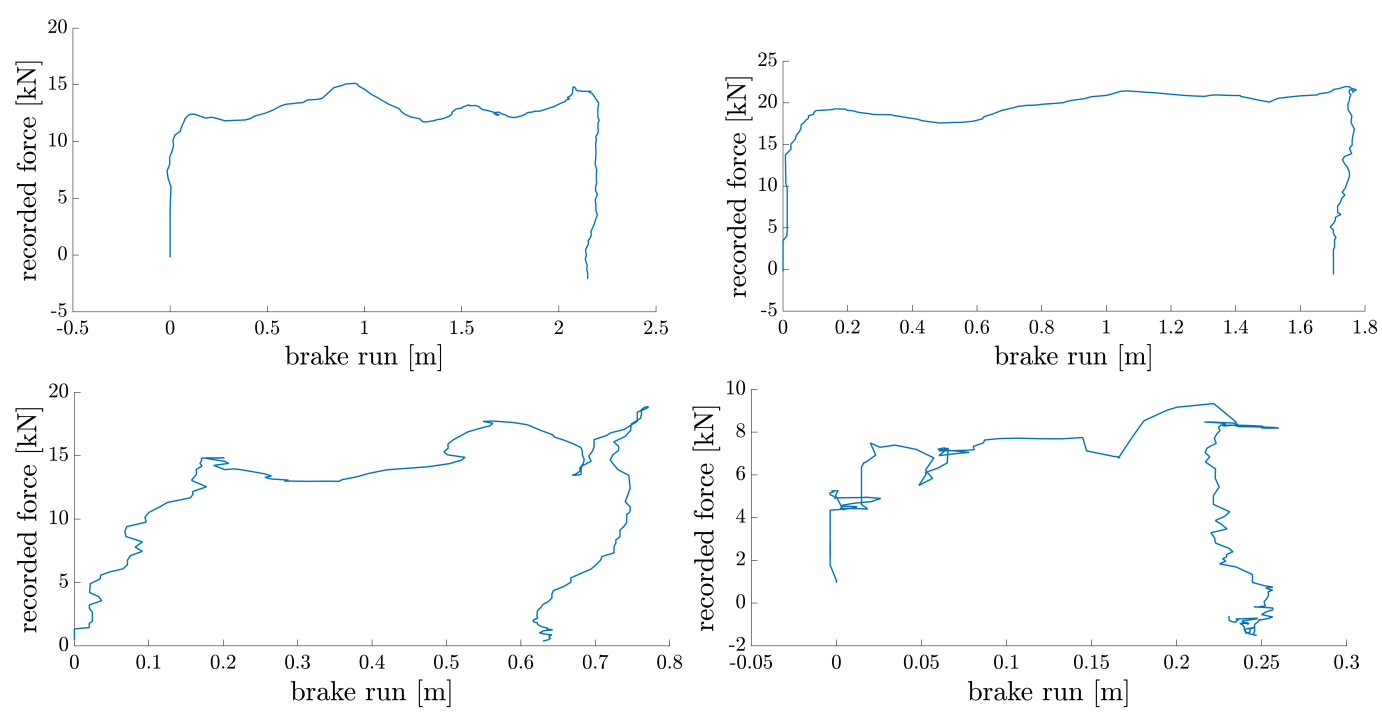

Figure 6. Four force-displacement diagrams used to determine brake-activation thresholds. For left to right and top to bottom: Off-centred impact, cable 3; off-centred impact, cable 1; lateral impact, cable 2; consecutive impact, cable 8. -pre-stress was taken into account.

The brake threshold distribution in Figure 7 with the characteristics displayed in Table 4 was determined from these values. A log-normal distribution of parameters $\mu=3.22$ and $\sigma^{2}=0.15$ was defined.

Table 4. Brake-activation threshold distributions.

\begin{tabular}{ccc}
\hline Standard Deviation & Average & Expected Value \\
\hline $10.8 \mathrm{kN}$ & $27.0 \mathrm{kN}$ & $27.0 \mathrm{kN}$ \\
\hline
\end{tabular}

The average value was close to the theoretical threshold defined by the manufacturer $(25 \mathrm{kN})$. One observes however that the dispersion was very large (around 40\%), which means that the hypothesis, currently admitted in numerical models, that all threshold values are equal, suffers some serious limitations as already suspected from the equivalent 
energy deduced in Tables 1 and 2. How this dispersion precisely influence the response of the barrier is the purpose of the proposed study. However, before conducting the numerical sensitivity analysis, it is necessary to present the numerical model used in the study, which is done in the coming section.

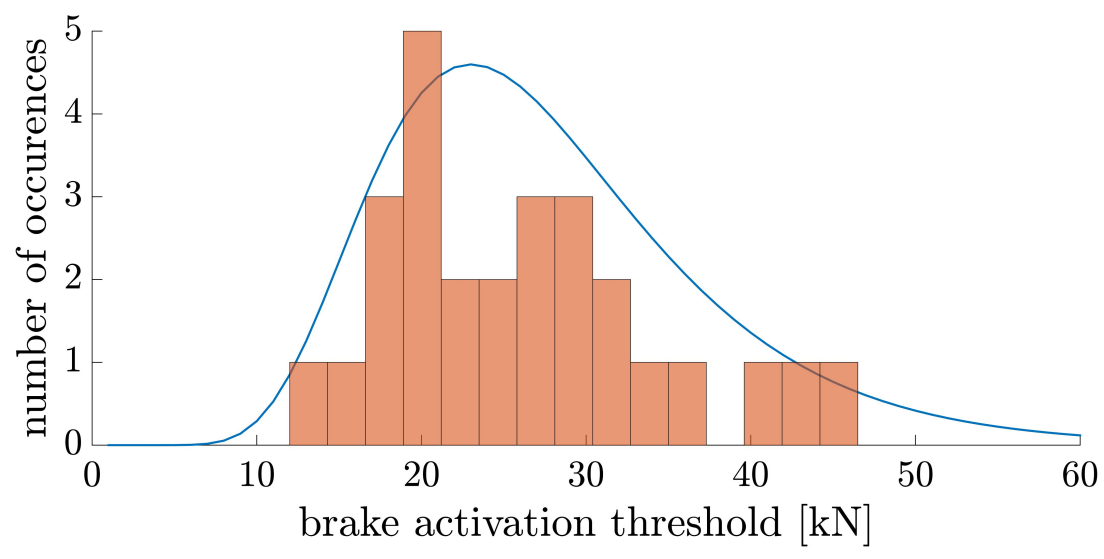

Figure 7. Distribution of experimentally measured brake-activation thresholds.

\section{Non-Linear Spring Mass System}

The starting point of the numerical model is a code that was already used for the rockfall barrier in two previous publications by the authors $[16,20]$ and which is therefore not recalled here. This tool is based on quasi-static calculations conducted by the dynamic relaxation method (Day [22]), an algorithm which is suited for the study of static equilibrium of structures with large displacements (Douthe and Baverel [23]).

\subsection{A dynamic Model Based on Finite Differences}

The mass of the net is distributed and about seven times smaller than the mass of the block that is concentrated in one point. In a first approximation, one could thus consider that the kinetic energy stored by the net is negligible compared to the kinetic energy of the block (which is completely true in the beginning where only the block moves). By there, it was decided to concentrate dynamical aspects of the barrier response in the dynamic of the block and, consequently, to consider the dynamics of the net as a second-order perturbation. The system becomes hence equivalent to a mass (the block) interacting with a complex spring (the net with its supporting structures), the reaction force of the spring being calculated from a quasi-static force applied by the net on the actual position of the block. A similar approach had been implemented in Grassl [24].

The algorithm goes hence as follows (see Figure 8):

(i) Start from a position $u_{i}(0)$, speed $\dot{u}_{i}(0)$, and initial acceleration $\ddot{u}_{i}(0)$ of the block. In all the simulations, the initial velocity and initial acceleration are always taken as purely vertical. Horizontal movement is allowed but is only caused by the reaction of the structure.

(ii) A small displacement is imposed $\delta_{i}(0)=\dot{u}_{i}(0) d t$, and the equilibrium solution is calculated according to the quasi-static analysis of the barrier.

(iii) From $R_{i}$, the reactions of the net on the block, the new position is calculated:

$$
\begin{array}{r}
\ddot{u}_{i}(t)=\frac{R_{i}}{m} \\
\dot{u}_{i}\left(t+\frac{d t}{2}\right)=\dot{u}_{i}\left(t-\frac{d t}{2}\right)+\ddot{u}_{i}(t) \times d t \\
u_{i}(t+d t)=u_{i}(t)+\dot{u}_{i}(t) \times d t+\ddot{u}_{i}(t) \times \frac{d t^{2}}{2}
\end{array}
$$

with $i=x, y$, or $z$ as the three dimensions of the block. 
(iv) The "brakes + cables" system following an elasto-plastic behaviour, and their properties are updated at each iteration.

(v) The algorithm stops when all edge cables start unloading.

This last issue is questionable as, when the cables start unloading, the structure is not at rest: elastic energy is still stored in the structure. It was however observed on the experimental data that, after this phase, there was no more plastic dissipation by the brakes and that the remaining elastic energy was slowly damped by the net and supporting structure by contact. In all the videos, the block was trapped by the deformed net and kept contact with it. This is the reason why this choice seemed legitimate in order to shorten the computing time without losing information on the energy dissipated by the brakes.

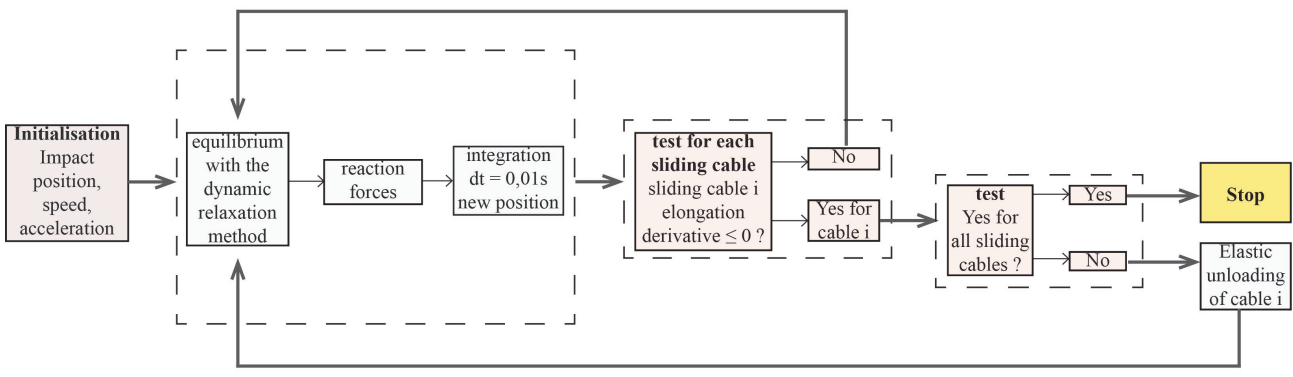

Figure 8. Equivalent spring-mass dynamic algorithm of the barrier.

\subsection{Limitation of the Structural Model}

The support cables were modelled using the sliding cable element developed by Boulaud et al. [20], which has no friction between the cables and the net. In this model, the only sources of dissipation were thus the brakes. This assumption was relatively strong because, in practice, part of the impact energy was dissipated by friction as documented in Coulibaly et al. [25] on a simple cable example or by the net itself $[9,10]$. However, the friction coefficient is a parameter that is independent from the other parameters concerned by the present sensitivity analysis (location of impact, prestress, and brake threshold). There might be couplings or interactions between parameters, but, in a first approximation, it was considered that interactions can be neglected and that the influence of parameters can be investigated independently.

Concerning the ASM4 ring net model, the simplest model was chosen with a spring representation of each ring interaction similarly to what is done in Nicot et al. [14] or Dugelas et al. [26]. The influence of this modelling choice was investigated in Boulaud and Douthe [16] who demonstrated that the ring model had a negligible influence on the global response of the barrier, which is driven by the deformation of supporting cables.

Concerning contact between the block and the net, non-penetration interactions are defined on the basis of proximity conditions between net nodes and the bottom of the block. Friction between the block and the net was neglected. High-speed camera images of the experiments show that this hypothesis is reasonable for impacts in the central module where the block exhibits almost no rotation movement. However, during the impact on the lateral module, one observes a significant rotation of the block, which necessarily implies that tangential forces are applied on its surface. The presented sensitivity analysis was thus less relevant for impact in the outer part of the barrier.

\subsection{Convergence Study}

The determination of the time step $d t$ was done through a convergence study for an off-centred impact at $(x, y)=(10.5,1.37)$. Considering a time step of $0.01 \mathrm{~s}$ and comparing it to a time step 10 times smaller, the difference in the calculation of the new positions was, at most, less than $2 \%$ of the value (for the position according to $z$ ). The value $d t=0.01 \mathrm{~s}$ was therefore considered appropriate, as shown in Figure 9. 

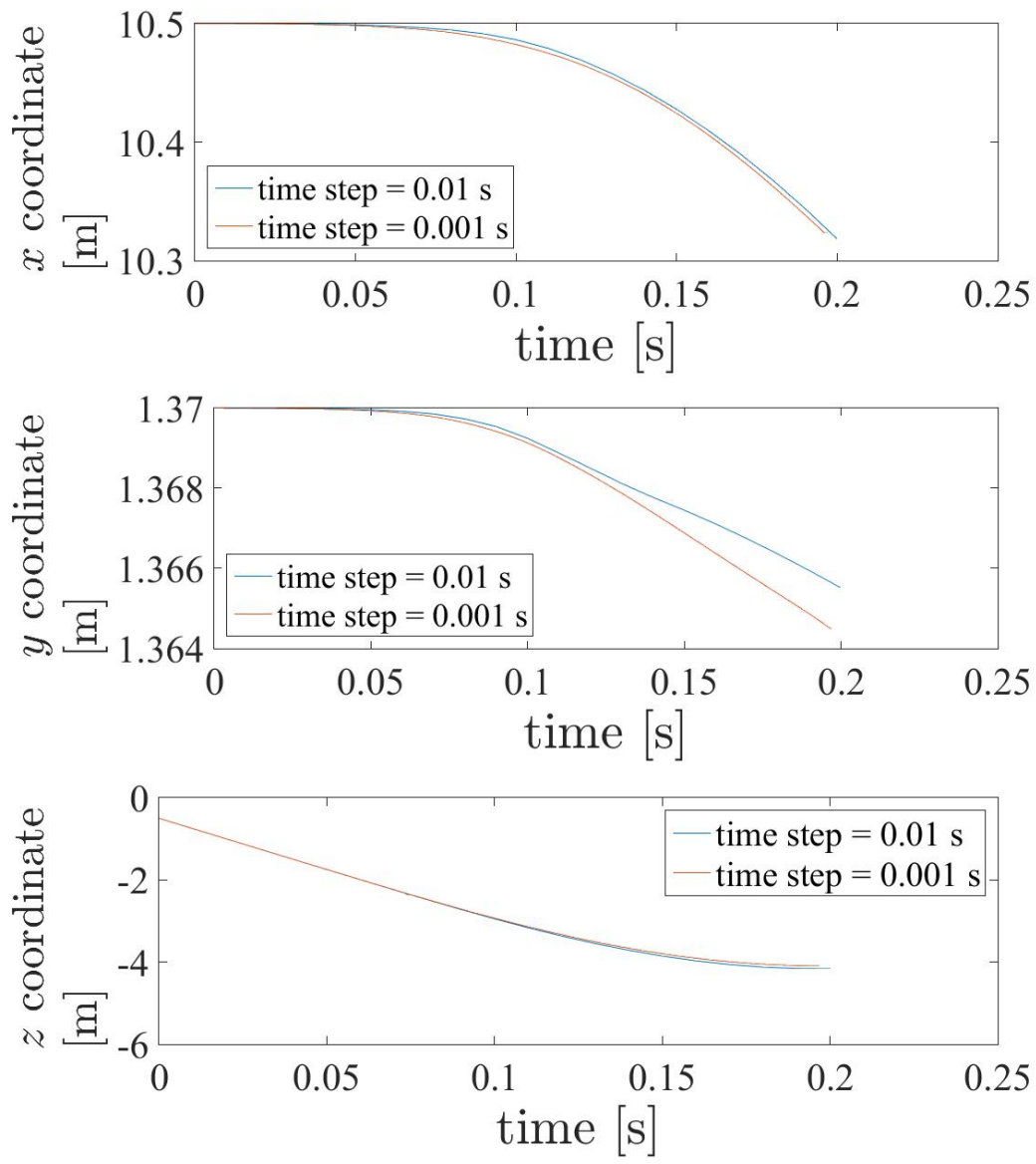

Figure 9. Position in the $x, y$ and $z$ directions as a function of time for $d t=0.01 \mathrm{~s}$ and $d t=0.001 \mathrm{~s}$.

\subsection{Validation by Comparison with a Few Characteristic Experimental Tests}

A few tests were performed to compare the accuracy of the model over time with the experimental data. The block trajectory for the MEL test is shown in Figure 10. The numerical solution fits the MEL 2 trajectory. Qualitatively, the dropping profile is the same. Quantitatively, the comparison was difficult because of the variability between the MEL 1 and MEL 2 tests. However, it can be concluded that the model reproduces reality quite well.

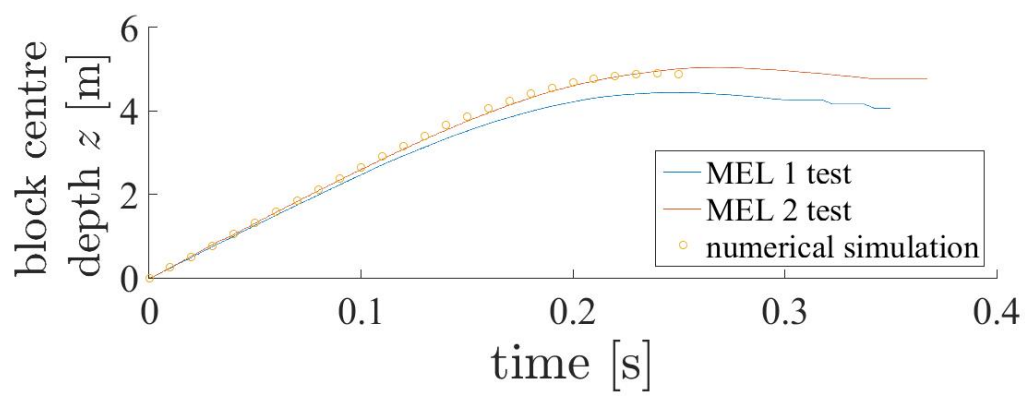

Figure 10. Displacement of the block centre as a function of time: MEL and numerical-test comparisons.

In a quantitative approach, the total brake elongation for experimental and numerical MEL tests is shown in Table 5. The numerical value is between the two experimental values. The order of magnitude was thus verified. 
Table 5. Total sum of brakes elongation comparison between MEL 1, MEL 2, and the numerical simulation.

\begin{tabular}{llll}
\hline Test & MEL 1 & MEL 2 & Num. Simulation \\
\hline total elongation & $828 \mathrm{~cm}$ & $1136 \mathrm{~cm}$ & $1004 \mathrm{~cm}$ \\
\hline
\end{tabular}

Figure 11 shows the numerically obtained elongations of the brakes over time compared to the actual elongations observed on the brakes during impact (measures were made using digital image correlation and visible elongation of brakes located at the cables end). Qualitatively, one can see that the triggering was happening in the range $t=[0.05 \mathrm{~s}$; $0.1 \mathrm{~s}$ ] in both cases. One also observes that the order of magnitude of elongations seemed consistent between the model and the experiment, the central cables being the most severely solicited. It was thus considered that the proposed simplified model is suitable to conduct the sensitivity analysis.
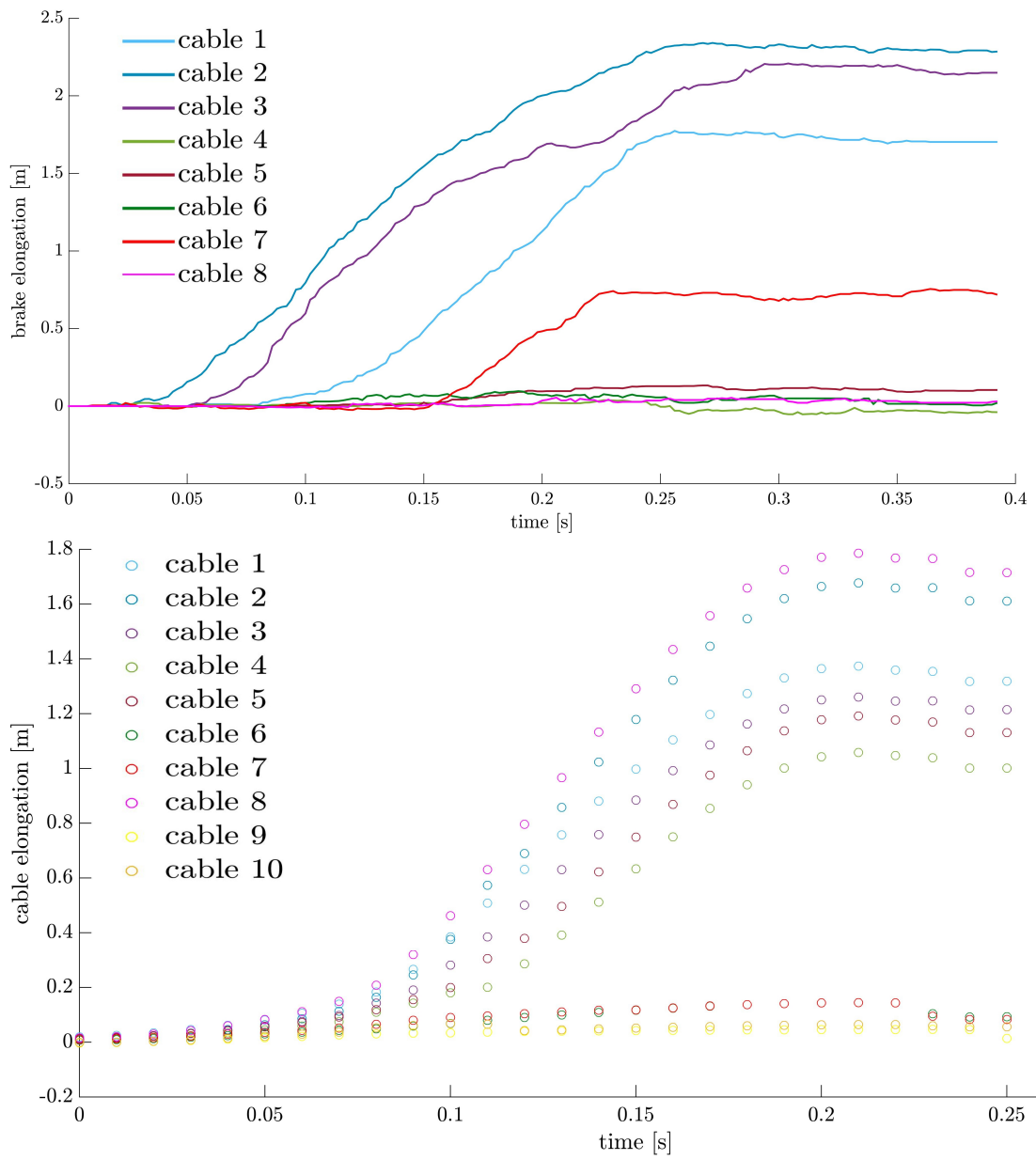

Figure 11. Above: Experimental brake elongation (off-centre impact) as a function of time. Below: Numerical brake elongation (off-centre impact) as a function of time.

\section{Sensitivity Analysis: Block-Related Parameters}

\subsection{Impact Position Variability}

The purpose of this first sensitivity analysis was to evaluate the variability of the dissipated energy, the maximum displacement reached by the block, and the residual height in relation to the displacement of the impact position on the surface of the net. The aim was to map the parameters of interest, in other words, to represent the values as a function of their position on the surface of the net. The mapped area is shown in Figure 4. It runs through the three units and covers the inner part of the net. The outer part of the net consists in a $0.5 \mathrm{~m}$ (resp. $1 \mathrm{~m}$ ) strip along the cable edges running in the $x$-direction 
(resp. $y$-direction) where there would be direct impact of the block on the supporting cables, which are phenomena not considered in the present study.

Then, as the number of measurements is limited, value interpolation is necessary: it must be ensured that this interpolation is possible. The interpolation (performed with the software MATLAB $\odot$ ) was verified by interpolating according to the natural neighbour interpolation method between some computed values and comparing the result of the interpolation with the actual computed values (see Table 6). The maximum error was below $3 \%$. This assumes that the model is sufficiently stable to be able to interpolate between the calculated values.

Table 6. Difference (in percentage) between the calculated values and the values obtained by interpolation.

\begin{tabular}{|c|c|c|c|c|}
\hline$X(\mathrm{~m})$ & $Y(\mathrm{~m})$ & $\frac{E_{d}}{E_{m, i}}$ Calculated (\%) & $\frac{E_{d}}{E_{m, i}}$ Interpolated (\%) & Difference (\%) \\
\hline 7.5 & 0.5 & 66.94 & 66.94 & 0.0 \\
\hline 7.5 & 1.37 & 70.18 & 68.69 & 2.13 \\
\hline 7.5 & 2.24 & 66.58 & 66.58 & 0.0 \\
\hline 9 & 0.935 & 75.49 & 75.49 & 0.0 \\
\hline 9 & 1.805 & 75.54 & 75.54 & 0.0 \\
\hline 10.5 & 0.5 & 75.69 & 77.84 & -2.84 \\
\hline 10.5 & 1.37 & 84.68 & 84.68 & 0.0 \\
\hline 10.5 & 2.24 & 76.31 & 77.76 & -1.91 \\
\hline 12 & 0.935 & 80.03 & 80.03 & 0.0 \\
\hline 12 & 1.805 & 79.94 & 79.94 & 0.0 \\
\hline
\end{tabular}

5.2. Maximum Displacement Reached by the Block Centre during the Impact and Equivalent Static Force

The goal was to evaluate an average braking force, as if the braking were constant over the duration of the total energy dissipation (even if this braking is by no means constant). The amplitude of this braking is calculated as an equivalent static force $F_{s, e q}$ based on the initial mechanical energy of the block $E_{M, i n i}$ over the braking distance $l\left(t_{e}\right)$.

At the time $t_{e}$ when all the energy is absorbed (either plastically by the brakes or elastically by the cables and the net), the block has moved a distance:

$$
l\left(t_{e}\right)=\sqrt{\left(x\left(t_{e}\right)-x_{0}\right)^{2}+\left(y\left(t_{e}\right)-y_{0}\right)^{2}+\left(z\left(t_{e}\right)-z_{0}\right)^{2}}
$$

The equivalent static force is then defined as follows:

$$
F_{s, e q}=\frac{E_{M, i n i}}{l\left(t_{e}\right)}
$$

where $E_{M, i n i}$ is the mechanical energy of the block at $t=0$ and with the static force oriented according to the block's displacement.

The equivalent static force is represented according to the point of impact in Figure 12. It is at its lowest in the centre of the net. The static force profile follows the stiffness of the net: it is smaller in the central (more flexible) areas of each net. 


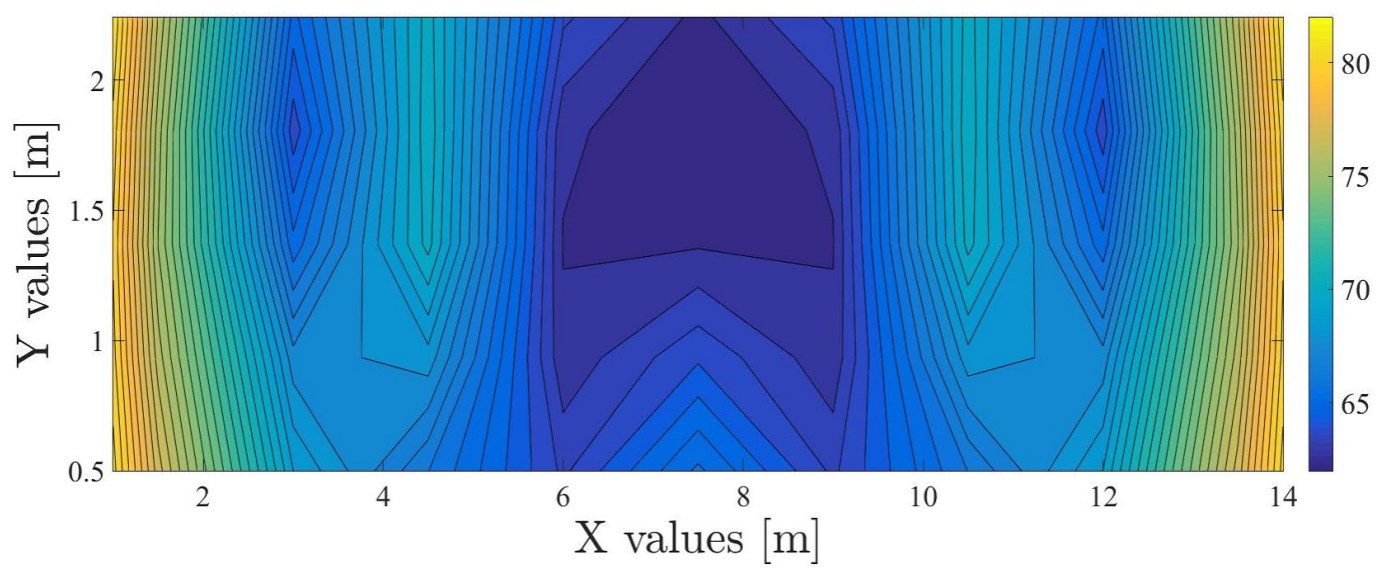

Figure 12. Mapping of the static force as a function of the impact position on the net $(\mathrm{kN})$ for an impacting energy $E_{M, i n i}$ of $270 \mathrm{~kJ}$.

Figure 13 shows the map illustrating the maximum displacement reached by the block during the impact as a function of the position of the centre of the block at the time of impact.

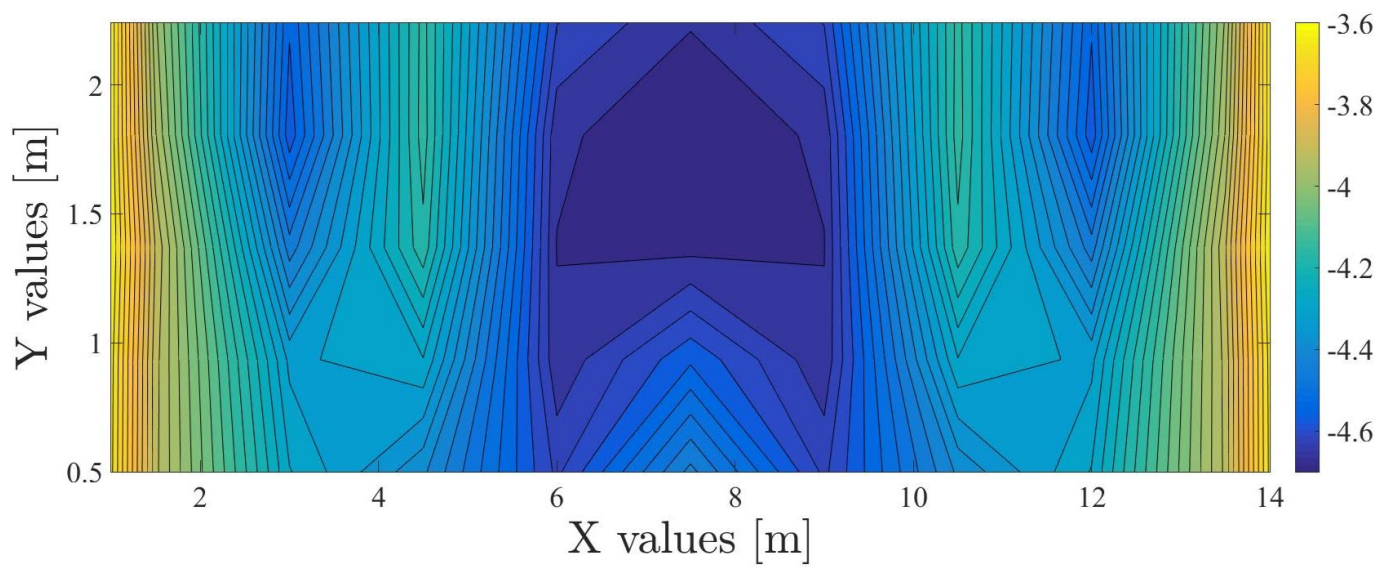

Figure 13. Mapping of the maximal displacement reached by the block centre as a function of the impact position on the net $(\mathrm{m})$ for an impacting energy $E_{M, i n i}$ of $270 \mathrm{~kJ}$.

The graph's appearance was very close to that of the equivalent static force. The correspondence with Figure 12 makes it possible to highlight that variations in mechanical energy to be dissipated according to impact zones are not significant, since the displacement $z$ is dominant to determine the static force of each point of the net. The lower the $z_{\max }$, the smaller the rigidity of the net. It is clear that the net is more flexible near the edge than near the cliff, as well as in the central areas of the net. The impact centred in $x$ is the most unfavourable case, but there is a variation in $y$ : it is when it is near the edge, opposite the cliff, that the block drops the lowest.

Figure 14 shows the block's displacement according to time. The error on the maximal displacement $z_{\max }$ was $3.6 \%$. However, the impact duration was significantly lower for the numerical study than for the experimental test. This observation might be related to the lack of friction in the numerical model, as friction and the associated damping slightly delay the response of the barrier. This difference might also be related to the small rotation and the associated lateral movement, which are less damped than the vertical movement. 


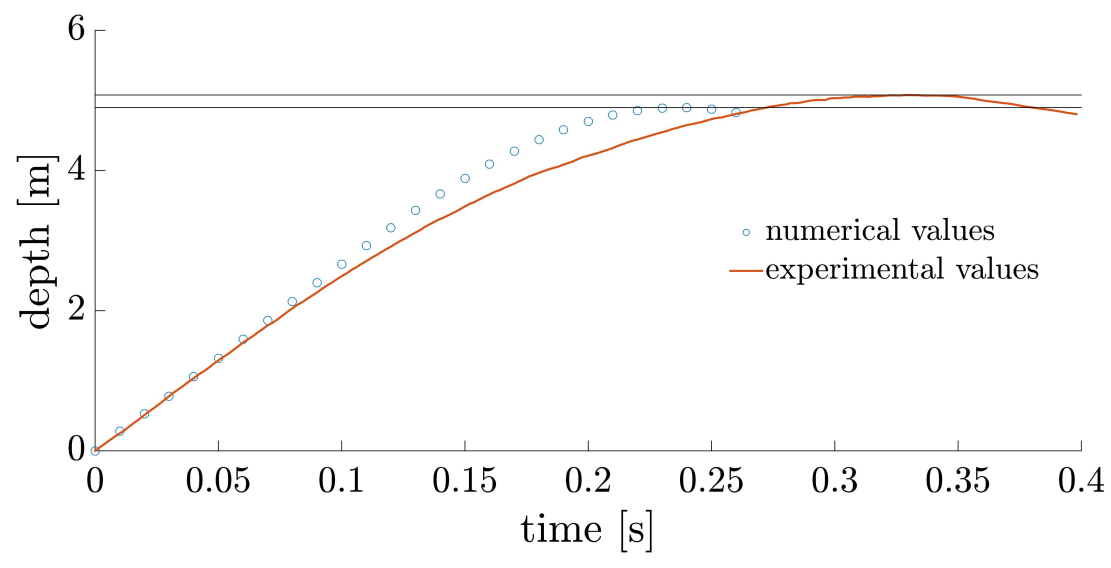

Figure 14. Off-centred impact: block's displacement according to time for an impacting energy of $270 \mathrm{~kJ}$.

\subsection{Total Energy Dissipated through the Brakes}

Figure 15 shows the ratio of the plastic energy dissipated by all the brakes at cables ends to the initial mechanical energy of the block at specific points in the net, supposing constant thresholds for all brakes. The $x$ coordinate of the impact is therefore shown on the abscissa and the $y$ coordinate on the ordinate. Each point is the position of the block centre at the time of impact. As a reminder, the ordinates near 0.5 correspond to the cliff side and the ordinates near 2.2 to the edge side.

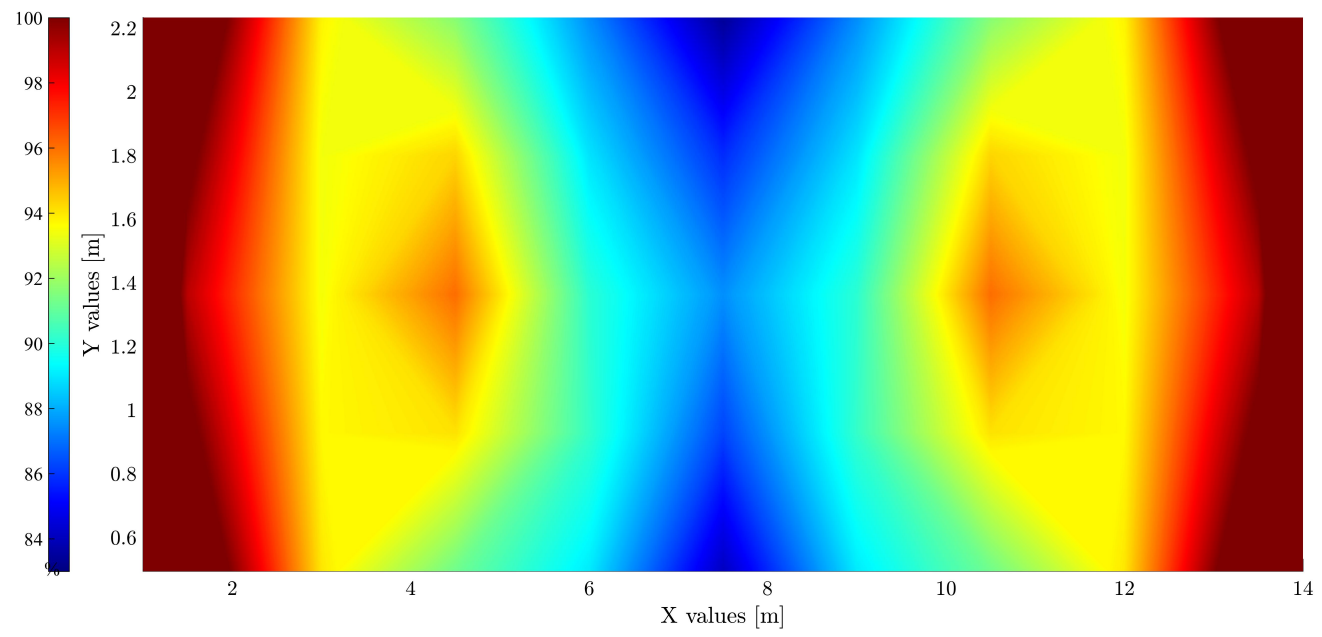

Figure 15. Percentage of plastically dissipated energy on the initial mechanical energy, supposing a constant threshold of brakes for an impacting energy of $270 \mathrm{~kJ}$.

The dissipated energies observed do not take into account the plastic deformation energy of the net (or rings).

There is strong symmetry at $y$ from the outset, despite asymmetry in reality due to cliff-side attachment points.

Considering that the higher the percentage of energy dissipated by the brakes, the lower the elastic energy stored by the barrier, one can deduce that, in the areas where the barrier configuration or architecture has large deformation capabilities (i.e., allows for large curtain effect), the brakes suffer less. Hence, it appears in Figure 15 that in the $x$ direction, the less demanding configuration for the brakes is the centred impact at $x=7.5 \mathrm{~m}$. In the $y$ direction, this statement needs to be qualified: as they approach the edges, cables dissipate less energy. The impact centred in $x$ and $y$ was reduced from $87.6 \%$ to $83.4 \%$ for $(x, y)=(7.5,2.24)$ and $84.1 \%$ for $(x, y)=(7.5,0.5)$. 
The impact that appears to be the most demanding for the brakes (i.e., where the most energy is dissipated by them) is an impact very close to the left or right extremities. Indeed, compared to the central module, the lateral modules or extremities can mobilise the elastic deformation capabilities of only the neighbour module (instead of two for the central module). Their capability to spread the load through the net is thus lower and their rigidity higher. This boundary case aside, another demanding case is the one where the impact is made near the poles (around $x=5 \mathrm{~m}$ or $x=10 \mathrm{~m}$ ), which are indeed other rigid areas of the barrier. Besides, one remarks that approaching the edges (cliff or edge side) causes less dissipation in the edge cables and brakes wherever one is on the net. In general, the maximum variation in energy dissipated is just over $15 \%$, and the most rigid areas dissipate the most.

\subsection{Distribution of the Energy Dissipated between the Various Brakes}

\subsubsection{Analysis of Numerical Results}

To go more into details, the percentage of energy dissipated plastically by each cable is represented in Figure 16. For each impact location, one can hence analyse the distribution of the energy between the various brakes and have a picture of the load paths from the impact point to the anchorages throughout the net. One remarks that:

- $\quad$ There are characteristic stripes on the maps, which denote an invariance along $y$ and the fact the the problem varies essentially according to $x$;

- The energy dissipation in the brakes is almost symmetrical according to $y$;

- On average, the impact closer to the cliff results in higher dissipation (nearly 5\% more) than the impact on the opposite side, which can be explained by the fact that the cliff side is more rigid because it is closer to the supports;

- When approaching the edge at $x=1 \mathrm{~m}$ or $x=14 \mathrm{~m}$, the brakes of the edge cables dissipate more than half of the block's initial mechanical energy;

- All brakes activate and dissipate a significant part of the impact energy for some impact location, meaning that, in the considered structure, all brakes are necessary and will be each the most solicited brake for a given impact location. 


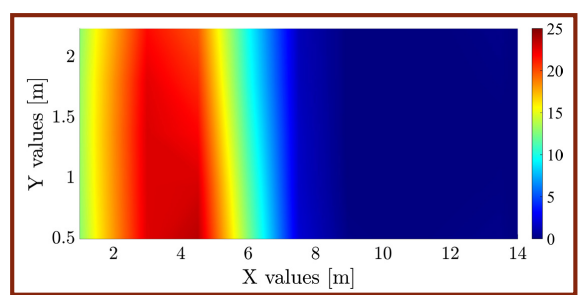

CABLE 7

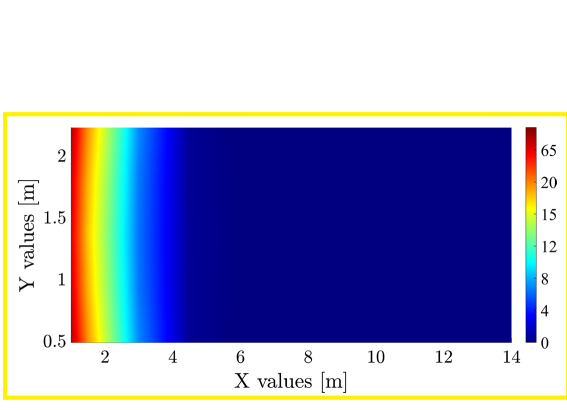

CABLE 9

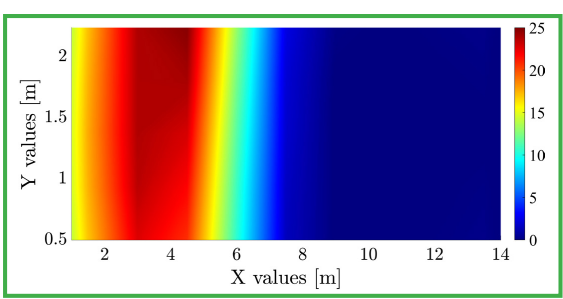

CABLE 6

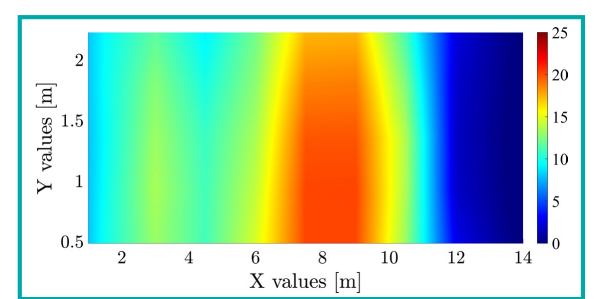

CABle 2

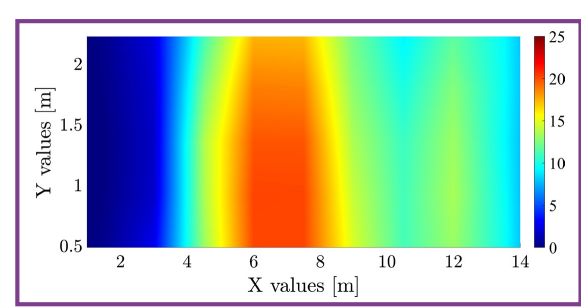

CABle 3

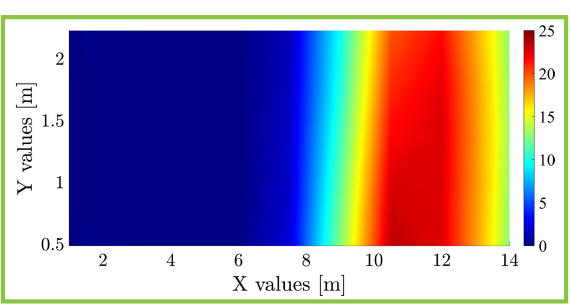

CABLE 4

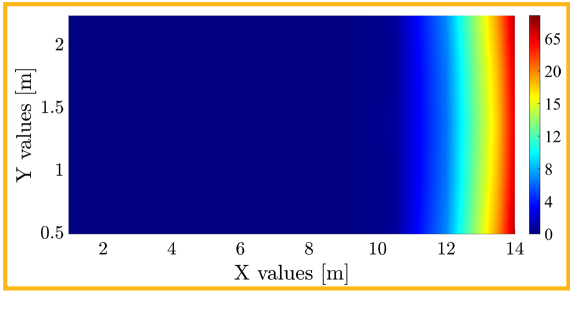

CABle 10

CLIFF

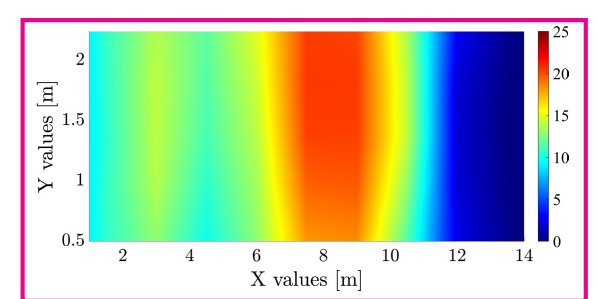

CABle 8

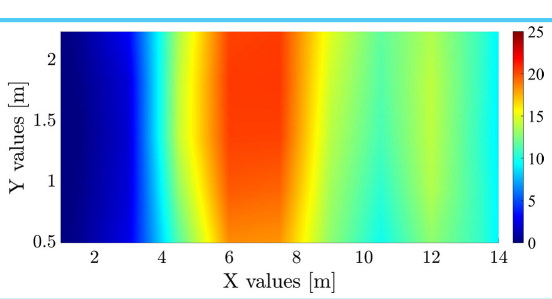

CABLE 1

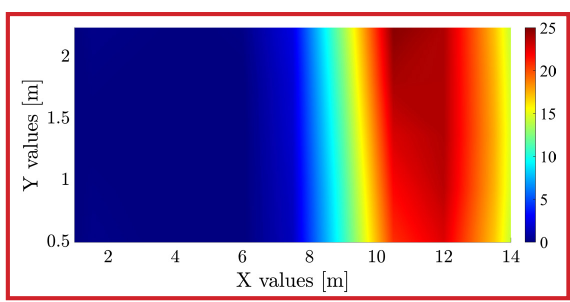

CABle 5

Figure 16. Percentage of the energy dissipated plastically in each cable on the initial mechanical energy, supposing a constant threshold of brakes. 


\subsubsection{Comparison with Experimental Results}

The elongations of brakes by cable for the off-centre test, in the experimental case and in the numerical case, are compiled in Table 7 . These elongations are first calculated by using, in the numerical simulation, the theoretical $25 \mathrm{kN}$ brake threshold. Qualitatively, one observed that the numerical model predicts well the brakes that are solicited during the impact. To go more into detail, one observes that there was a significant difference for cables 2 and 3, while this difference was reduced for all other cables. Looking at the activation thresholds measured during the experiment, for cable 2, there was a brake threshold at $F_{s, 2}=14.5 \mathrm{kN}$ and for cable 3 a brake threshold at $F_{s, 3}=12.8 \mathrm{kN}$. By adjusting the threshold values (see the last line of the table), the difference between the experimental and the numerical values for those two cables falls down to a comparable level. Unfortunately, the number of force sensors in the structure did not allow for the measuring of all the thresholds, and it was not possible to proceed in the same way with all the cables. Nevertheless, it appears clearly that the knowledge of the exact threshold is key to the prediction of the brake elongation.

Table 7. Brake elongations by the cable number for the off-centred test.

\begin{tabular}{lllllllllll}
\hline \multirow{2}{*}{ Cable No. } & $\mathbf{1}$ & $\mathbf{2}$ & $\mathbf{3}$ & $\mathbf{4}$ & $\mathbf{5}$ & $\mathbf{6}$ & $\mathbf{7}$ & $\mathbf{8}$ & $\mathbf{9}$ & $\mathbf{1 0}$ \\
& Edge & Cliff & Cliff & Cliff & Edge & Edge & Cliff & Edge & Lat. & Lat. \\
\hline Exp. $(\mathrm{cm})$ & 174 & 340 & 301 & 75 & 107 & 0 & 15 & 198 & 0 & 0 \\
\hline Num. $(\mathrm{cm})$ & 158 & 204 & 159 & 118 & 133 & 15 & 14 & 197 & 5 & 9 \\
\hline Num. mod. $(\mathrm{cm})$ & 158 & 320 & 290 & 118 & 133 & 15 & 14 & 197 & 5 & 9 \\
\hline
\end{tabular}

During the experiment with a lateral impact, no cliff-side cables ran. For an unknown reason, the brakes seemed to be completely blocked. There are therefore significant differences between numerical simulation and real testing. These differences are less pronounced when summing the elongations of the brakes of symmetric cables according to $y$, as shown in Table 8. A proportion of the energy that could not be dissipated by the blocked brakes is found in their symmetric brakes. Globally, the differences observed for the brake elongations for the lateral test are comparable to those observed for the off-centred test, except for cable 10. These differences might thus be attributed to the effective threshold values of brakes.

Table 8. Brake elongations by cable number grouping cable by pairs in the $y$ direction for the lateral impact.

\begin{tabular}{lllllll}
\hline Cable Couple & $\mathbf{1 + 3}$ & $\mathbf{2 + 8}$ & $\mathbf{4 + 5}$ & $\mathbf{6 + 7}$ & $\mathbf{9}$ & $\mathbf{1 0}$ \\
\hline Exp. $(\mathrm{cm})$ & 0 & 173 & 0 & 230 & 71 & 0 \\
\hline Num. $(\mathrm{cm})$ & 29 & 236 & 12 & 344 & 269 & 2 \\
\hline
\end{tabular}

To explain the very large difference in cable 9, the detailed arrangement of the net, cables, and brakes was studied. It shows that these cables are looped (see Figure 2). To build these loops, the lateral cables pass through shackles with a relatively sharp angle, which hinders their sliding by friction. A more realistic numerical model was thus built by introducing friction at the head and bases of the post for these lateral cables. The force in the cable will then depend on the angle $\alpha$ of this cable over time and of the activation threshold $F_{S}$ of the brake (see Figure 17).

$$
F_{S} \cdot \delta+F_{S} \cdot\left(e^{\mu \alpha}-1\right) \cdot \delta=F_{S} \cdot e^{\mu \alpha} \cdot \delta
$$

with $\mu=0.3$ as the friction coefficient and $\delta$ as the brake elongation. 


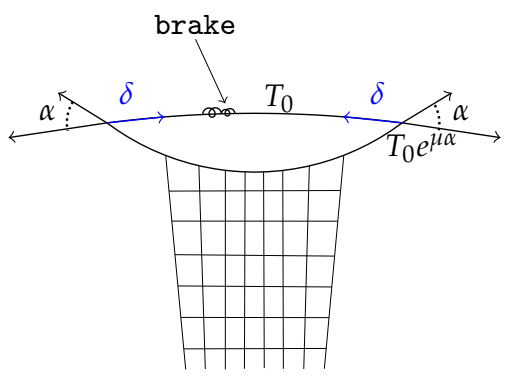

net

Figure 17. Detailed scheme of lateral cables (9 or 10) showing characteristic angles at shackles.

Adding this adjustment to the cable behaviour of the side cables reduces the total brake elongation of cable 9 by $60 \%$. The difference between numerical and experimental elongation becomes hence comparable to other cables and can be attributed to the discrepancy of threshold values (whose influence is discussed in the next section).

An attempt was then made to reproduce properly the lateral test as it was experimentally observed: in other words, by adjusting the value of the thresholds to those measured and by putting an infinite threshold on the cables on the cliff side. As friction was not taken into account in the simulation, the block can roll freely on the net and eventually leave the net web (see Figure 18). By blocking on one side, a very strong asymmetry was introduced, which highlights the need to model the friction at the contact between the block and the net when the horizontal acceleration becomes significant. This should be considered in further work.

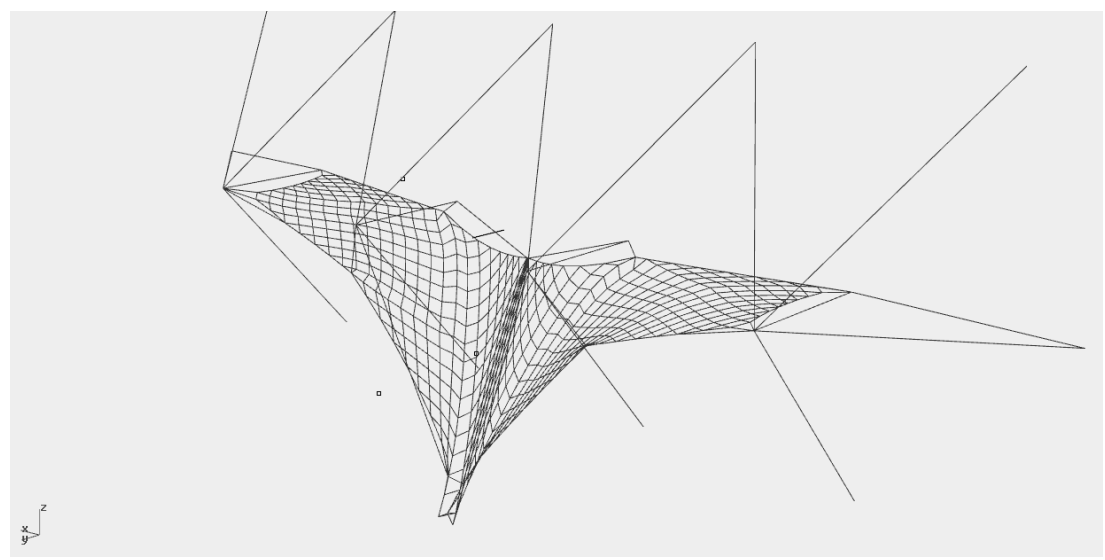

Figure 18. Net with cliff-side cables blocked and block fallen off the net.

\subsection{Residual Height $h_{r}$}

The residual height as a function of the impact position of the block is plotted on Figure 19. It represents the smallest height of the barrier taken perpendicularly to the cliff when all the energy has been dissipated. To obtain these results, the previous calculations were conducted one step further, and the equilibrium configurations under gravity load with the computed brake elongations were calculated.

As expected, the residual height was greater in the most rigid areas (i.e., where the net deforms less). However, there was a local maximum for the centred impact. This can be explained by the symmetry of the system: the cables on each side are less stressed at one time and therefore deform less plastically, while for the off-centre impact in $y$, the cables on one side are very stressed and deform strongly and then, when they unload, do not regain their initial length since in the plastic domain. This effect does not occur in the centre of the side nets: at this location, the length of the cable's attachment to the net is much shorter (cables 4, 5, 6, and 7) than the for dissipating cables of the centred impact (cables 1, 2, 3, 
and 8). They can therefore stretch less in the plane $(x, z)$ and deform more in the plane $(y, z)$. This results in a lower residual height (i.e., a higher proximity of the opposite edge cables).

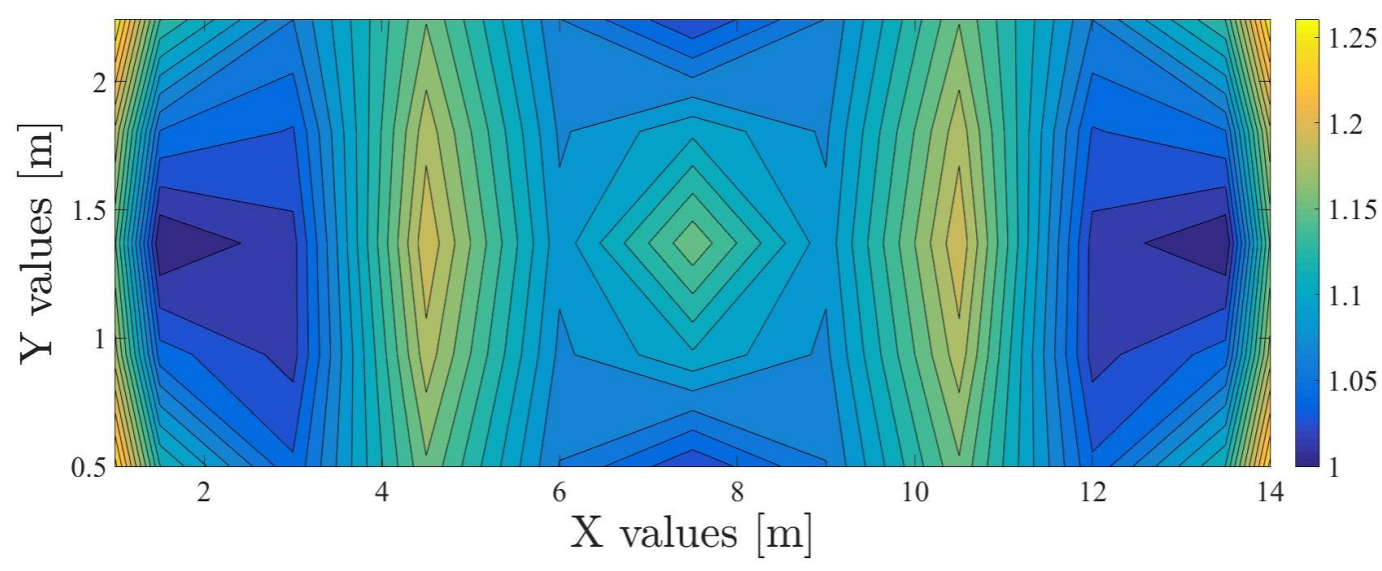

Figure 19. Mapping of the residual height as a function of the impact position on the net (m).

Comparing then the numerical values with the experimental ones (see Table 9), one observes that the agreement is very good, especially when friction is taken into account for the lateral cables. This confirms the relevance of this simple model for reproducing the global response of the flexible barrier.

Table 9. Residual height for the off-centred impact and the lateral impact.

\begin{tabular}{llll}
\hline Impact & Exp. Height & Num. Height & Diff. \\
\hline off-centred impact & $1.01 \mathrm{~m}$ & $1.03 \mathrm{~m}$ & $1.9 \%$ \\
\hline lateral impact & $0.94 \mathrm{~m}$ & $0.84 \mathrm{~m}$ & $11.2 \%$ \\
\hline lateral + friction & $0.94 \mathrm{~m}$ & $0.92 \mathrm{~m}$ & $2.1 \%$ \\
\hline
\end{tabular}

It is important to note that, in the case of impacts near the lateral edges, the notion of residual height is no longer sufficient (as shown on Figure 20). Indeed, because of the curtain effect on the side cable and of its deformation, a hole forms on the side of the barrier. It might thus be interesting for those impacts to define a residual width of the barrier.

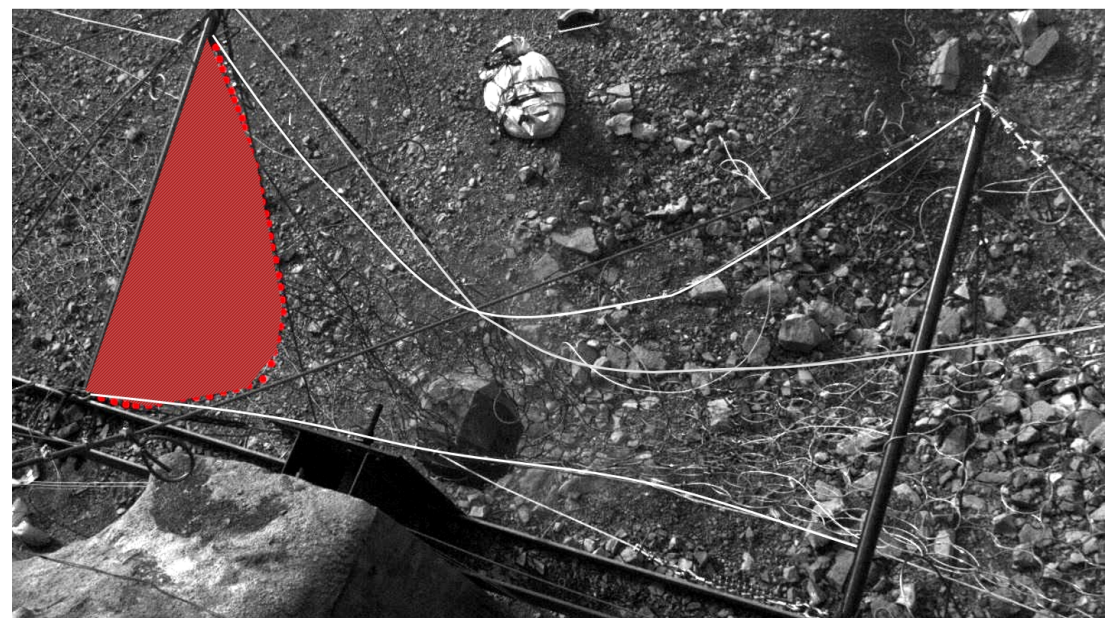

Figure 20. Side hole in the barrier after the lateral impact during the second campaign.

\section{Sensitivity Analysis: Net-Related Parameters}

After studying the influence of the impact position of the block, the effects related to the dispersion of some of the supporting cable parameters were examined. 


\subsection{Prestress Variability}

In order to explore the influence of the prestress level on the main impact characteristics (energy dissipation, maximum displacement, and residual height), a prestress distribution was randomly applied on the cables. This prestress distribution follows the law determined experimentally (see Section 3.3). Practically, it takes the form of a length default: $\Delta l=\frac{F_{\text {pre-load }} \cdot l_{0}}{E_{S} S}$. The barrier being hyperstatic, the effective distribution of the prestress at iteration $i=1$ resulting from these length defaults was not exactly the desired one. However, one can verify on a single example that the prestress only rearranged marginally in the structure (see Table 10) and that the order of magnitude and the statistical distribution were similar. Especially, the larger the prestress level, the lower the difference between the target value and the equilibrium state.

Table 10. Prestress in supporting cables: target level $(i=0)$ and practical equilibrium state $(i=1)$.

\begin{tabular}{cccc}
\hline Cable & Input at $\boldsymbol{i}=\mathbf{0}(\mathbf{k N})$ & Equilibrium at $\boldsymbol{i}=\mathbf{1}(\mathbf{k N})$ & Difference $(\mathbf{k N})$ \\
\hline 1 & 8.6 & 9.5 & 0.9 \\
2 & 4.7 & 6.3 & 1.6 \\
3 & 0.7 & 2.9 & 2.2 \\
4 & 7.0 & 7.3 & 0.3 \\
5 & 5.3 & 5.9 & 0.7 \\
6 & 10.4 & 10.9 & 0.5 \\
7 & 1.8 & 3.1 & 1.3 \\
8 & 6.0 & 6.9 & 0.8 \\
9 & 4.4 & 5.2 & 0.8 \\
10 & 8.6 & 8.9 & 0.4 \\
\hline Average & 5.7 & 6.7 & 1.0 \\
\hline
\end{tabular}

About ten numerical simulations were performed, the results of which are presented in Figures 21 and 22. Figure 21 illustrates the variation in the amount of energy dissipated by a cable for different prestress values applied to this cable in the case of a centred test. It appears that the increase in the prestress of a cable has almost no influence on the amount of plastic energy dissipated by this cable (dots are almost vertically aligned). Indeed, during the impact, the cables rearranged, and the final equilibrium was the same. However, for cables with very low prestressing (typically below $3 \mathrm{kN}$ ), the amount of energy dissipated for these cable decreased significantly. Considering that the cable stiffness under lateral load at the time of impact was directly linked with their geometric stiffness: the higher the initial prestress, the higher the cable stiffness. Considering then that the structure is hyperstatic, it is well-known that, in hyperstatic structures, stiffness attracts forces. It seems thus natural that when the structure is unequally prestressed, forces should be attracted by the most prestressed cables, resulting in some small variations in load paths through the net, which has time to deform significantly before tensions in the less prestressed cables reach the threshold value and start dissipating energy.

This result was also found at a global scale as shown in Figure 22: the higher the average prestress level, the larger the amount of energy dissipated by the brakes (about a $20 \%$ increase approximately). A high global prestress level provides a higher initial stiffness of the barrier, which will start dissipating earlier. The global response of the barrier is not modified, only the share between plastic energy dissipated by the brakes and elastic energy stored by the components changes. 


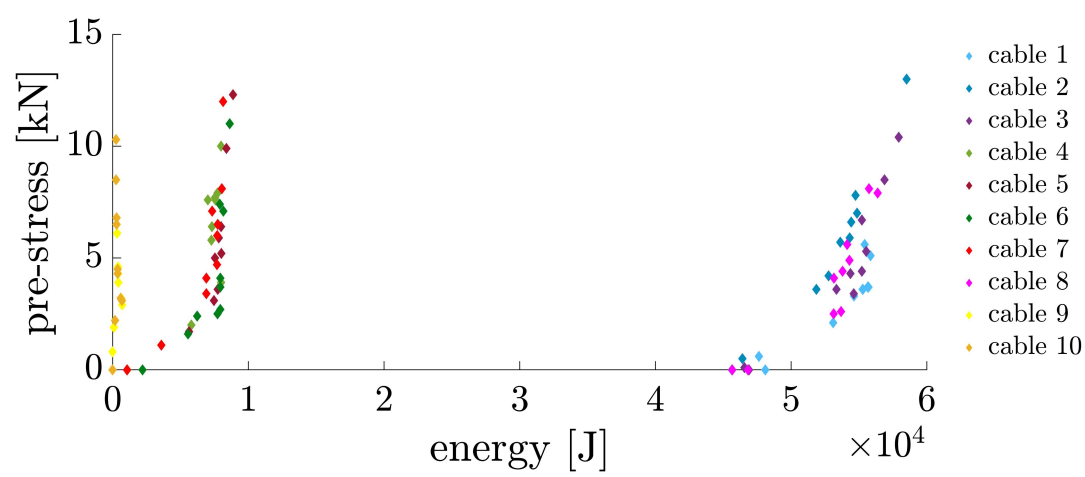

Figure 21. Locally dissipated energy according to prestress in each cable.

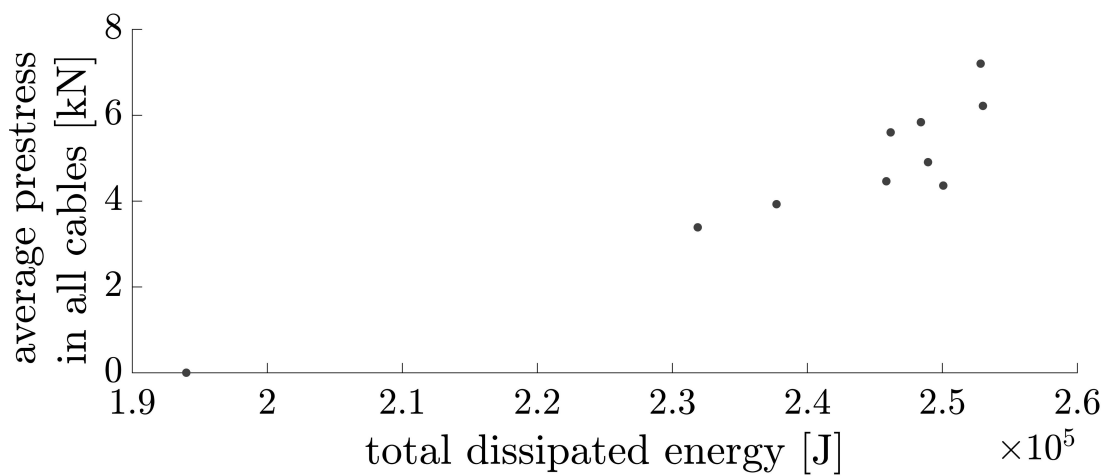

Figure 22. Global energy variation according to the average prestress in all cables.

\subsection{Variability Due to Uncertainty on Brake-Activation Thresholds}

In order to explore the influence of brake threshold variations on the main impact characteristics (energy dissipation, maximum displacement, and residual height), a brake threshold distribution was randomly applied on the cables. This threshold distribution follows the law determined experimentally (see Section 3.4).

The local study of the influence of the threshold is shown in Figure 23, where for each cable, the energy dissipated by this cable is represented as a function of the brake-activation threshold whose value was given by the manufacturer as $25 \mathrm{kN}$. As expected, one observes that the dissipated energy is almost proportional to the brake threshold. Variations in the dissipated energy are significant, and, for example, in the test sample, the energy dissipated by cable 8 varied from $1.70 \mathrm{~kJ}$ (when the threshold was $5 \mathrm{kN}$ ) to $5.2 \mathrm{~kJ}$ (for the threshold of $42 \mathrm{kN})$.

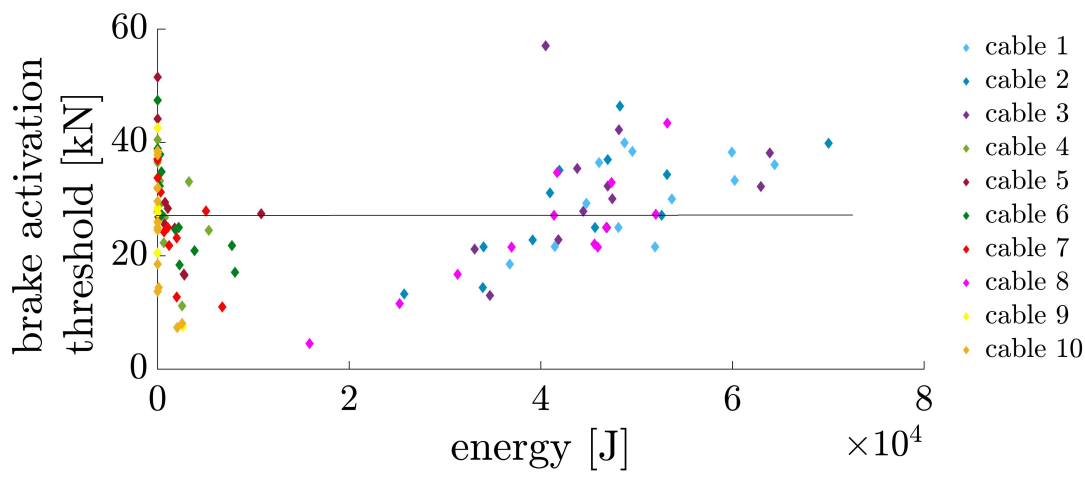

Figure 23. Local dissipated energy variations according to brake-activation threshold in each cable.

Globally, Figure 24 represents the average of the thresholds for a simulation as a function of the total energy dissipated during the impact. Here, it can be seen that the higher the average brake activation threshold, the less dissipation there is, and vice versa: 
that is, when all the brakes are triggered later, the amount of energy dissipated is lower. Considering that the global deformation increases with time and, by there, that the strain energy increases with time, one might suppose that the later the triggering of the brakes, the higher the share of elastic strain energy (or equivalently the smaller the dissipated energy). Moreover, as the barrier deforms, the cables incline, and the vertical component of the braking forces increase: the more vertical the braking force, the more efficient the dissipation. The dissipation being more effective, the dissipation needs are also reduced.

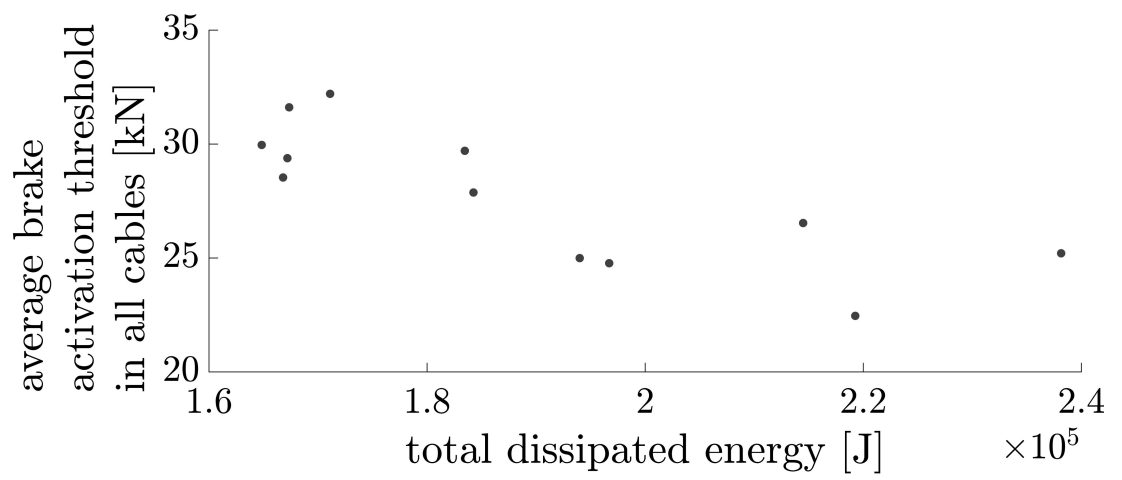

Figure 24. Global energy variation according to the average brake-activation threshold in all cables.

This shows that the efficiency of the structure is closely linked with its geometric stiffness, which combines the large deformation with the intensity of the forces in the cables, i.e., with the brake thresholds. Indeed, the geometric stiffness allies the working force in the cable with its direction change: the higher the brake threshold, the stiffer the cables; the stiffer the cables, the lower the elastic strain energy in the net and the higher the dissipated energy by the brakes.

\section{Discussion}

Table 11 compiles, in percentage terms, the standard deviations and maximum deviations obtained during the series of measurements analysed in the previous sections. It can be noted that pre-stressing is indeed not a dominant factor for the variability of the results, since the standard deviations were systematically below $3 \%$. On the contrary, the position of the block impact is significant, especially for the values of residual height and maximum displacement. The variation in the thresholds is significant as well: the maximum observed differences in the amount of energy dissipated were almost $40 \%$.

Table 11. Variability due to impact position, prestress, and brake-activation threshold uncertainties.

\begin{tabular}{lllll}
\hline Variable & & Prestress & Brake Threshold & Impact Position \\
\hline Energy & Std dev. & $2.9 \%$ & $\mathbf{1 3 . 5 \%}$ & $8.1 \%$ \\
& Max. dev. & $8.6 \%$ & $\mathbf{3 8 . 9} \%$ & $26.1 \%$ \\
\hline \multirow{2}{*}{ Max. Displ } & Std dev. & $0.3 \%$ & $2.7 \%$ & $\mathbf{8 . 6 \%}$ \\
& Max. dev. & $0.9 \%$ & $8.6 \%$ & $\mathbf{2 4 . 2 \%}$ \\
\hline \multirow{2}{*}{ Res. Height } & Std dev. & $1.6 \%$ & $6.2 \%$ & $\mathbf{7 . 9 \%}$ \\
& Max. dev. & $5.3 \%$ & $18.2 \%$ & $\mathbf{2 3 . 1 \%}$ \\
\hline
\end{tabular}

The variability observed in the experimental tests was very pronounced. Considering the decisive parameters for the validation of a barrier, according to the ETAG, the following differences were obtained for the MEL tests alone:

- Energy dissipated : $\pm 29 \%$

- Maximum displacement: $\pm 13 \%$

- Residual height: $\pm 16 \%$ 
Regarding the energy dissipated and the residual height, the deviation remained well below the maximum differences observed numerically. The difference in terms of maximum displacement, on the other hand, was very large-a few explanations are possible. First, the MEL impacts, even if they are supposed to have occurred in exactly the same place, can be considered to have been somewhat delayed, and a variation due to position was not taken into account; second, the number of measurements to provide the values in Table 11, although representative, are not sufficient to make a true statistical study, and the range given is therefore inaccurate. Finally, the inaccuracies due to the measure itself are not negligible (as stated in Section 2.2, brake-elongation uncertainties were estimated to approximately $4.5 \%$ ). Considering this, the difference between the maximum displacements remains within the range defined in the Table 11.

\section{Conclusions}

The analysis of both C2ROP project test campaigns revealed a high variability in residual height, maximum displacement, and cable running values. To understand this variability, a sensibility analysis was conducted numerically using a model in which the dynamics of the system were implemented in the form of a non-linear mass/spring system. The relevance of this model was tested and validated with comparison with the experimental results.

The first phase of the sensitivity analysis concerned the influence of the impact position of the block. It was shown that, for the studied fence, each cable is important, and each brake is activated for some impact position (see Figure 16), so that all the brakes are necessary at some points. The centred impact is, according to the study, the most unfavourable (the one which exhibits the highest deformation), so that the ETAG is indeed safe.

The second phase of the sensitivity analysis was investigated: first, the influence of the prestress applied to the edge cables, then that of brake thresholds. Concerning the prestress, even if the dispersion of the values was large (more than $50 \%$ ), the influence was found of a secondary order on the global response of the fence. Concerning the variation in brake thresholds, their dispersion was smaller (less than $40 \%$ ) but by far had more significant influence, with a standard deviation on dissipated energy of $13.5 \%$ and a maximum deviation among the simulations performed of nearly $40 \%$.

Some general comments on the fence structural behaviour can hence be drawn. The key issue in the design of flexible rockfall barrier is its architecture: it is the arrangement of the supporting cables that drives the way the structure deforms from a planar to three-dimensional network. The modelling choices of the net have little influence on the response, provided that the sliding of the cable is correctly taken into account [16]. It is the architecture of the fence and the sliding that guarantee its ability to adapt its geometry to the position of the impact so that it can resist the load with reasonable internal forces in the system.

The efficiency of the structure is then principally linked with its geometric stiffness, which combines the working force in the cable (given by the brake threshold) with its direction change. The prestress level can be seen as a kind of initial geometric imperfection, like the position of the post head, the ring arrangement variation, or a small pre-loading of the net.

To conclude, there is a trend in the community toward the definition of safety coefficients for such protective fences. It seems thus that, beside perforation issues, which were not in the scope of this study, one way to improve the reliability of a flexible rockfall barrier would be to improve the brake reliability. Indeed, by diminishing the threshold dispersion, one would reduce the dispersion of the barrier response (maximal displacement and residual height) and thereby reduce the statistical consequences of this dispersion on safety factors.

Author Contributions: Conceptualization: C.D., C.G. and R.B.; methodology, C.D., C.G. and R.B.; software : C.G. and R.B.; validation C.D., C.G. and R.B.; formal analysis: C.D. and C.G.; investigation C.D., C.G. and R.B.; resources, C.D.; data curation, C.G.; writing—original draft preparation, C.D. 
and C.G.; writing-review and editing, C.D.; visualization, C.D. and C.G.; supervision, C.D.; project administration, C.D.; funding acquisition, C.D. All authors have read and agreed to the published version of the manuscript.

Funding: This research received no external funding.

Data Availability Statement: Not applicable.

Acknowledgments: The authors wish to thank all the members of the national project C2ROP and particularly the members of the working group on flexible barriers for their invaluable support, namely, M-A. Chanut and J. Coulibaly from CEREMA; P. Robit and I. Olmedo from the NGE Foundation; C. Galandrin and M. Verdet from CAN; L. Dugelas, and S. Lambert from INRAE; and D. Bertrand from INSA Lyon.

Conflicts of Interest: The authors declare no conflict of interest.

\section{References}

1. Volkwein, A.; Schellenberg, K.; Labiouse, V.; Agliardi, F.; Berger, F.; Bourrier, F.; Dorren, L.K.A.; Gerber, W.; Jaboyedoff, M. Rockfall characterisation and structural protection-A review. Nat. Hazards Earth Syst. Sci. 2011, 11, 2617-2651. [CrossRef]

2. Yang, J.; Duan, S.; Li, Q.; Liu, C. A review of flexible protection in rockfall protection. Nat. Hazards 2019, 99, 71-89. [CrossRef]

3. Muraishi, H.; Samizo, M.; Sugiyama, T. Development of a flexible low-energy rockfall protection fence. Q. Rep. RTRI 2005, 46, 161-166. [CrossRef]

4. McCauley, M.L.; Works, B.W.; Naramore, S.A. Rockfall Mitigation. Final Report; Technical Report, FHWA/CA/TL-85/12, 54322-632173; Federal Highway Administration: Washington, DC, USA, 1985.

5. Peila, D.; Pelizza, S.; Sassudelli, F. Evaluation of Behaviour of Rockfall Restraining Nets by Full Scale Tests. Rock Mech. Rock Eng. 1998, 31, 1-24. [CrossRef]

6. Gerber, W.; Grassl, H.; Boell, A.; Ammann, W. Flexible rockfall barriers development, standardisation and type-testing in switzerland. In Landslides Causes, Impacts and Countermeasures; Kuehne, M., Ed.; United Engineering Foundation, Inc.: Davos, Switzerland, 2001.

7. Muraishi, H.; Sano, S. Full-scale rockfall test of ring net barrier and components. In Seminar on Rock Fall Tests and Stabilization; Davos, Switzerland, 1999.

8. Grassl, H.; Volkwein, A.; Anderheggen, E.; Ammann, W.J. Steel-Net Rockfall Protection-Experimental and Numerical Simulation; Jones, N., Brebbia, C.A., Rajendran, A.M.; Eds.; Structures Under Shock and Impact VII; WIT Press: Billerica, MA, USA, 2002; p. 593; ISBN 1-85312-911-9. [CrossRef]

9. Trad, A. Analyse du Comportement et Modélisation de Structures Souples de Protection: Le cas des Ecrans de Filets Pare-Pierre sous Sollicitations Statique et Dynamique. Ph.D. Thesis, INSA de Lyon, Villeurbanne, France, 2011.

10. Bertrand, D.; Trad, A.; Limam, A.; Silvani, C. Full-Scale Dynamic Analysis of an Innovative Rockfall Fence Under Impact Using the Discrete Element Method: From the Local Scale to the Structure Scale. Rock Mech. Rock Eng. 2012, 45, 885-900. [CrossRef]

11. EOTA. ETAG-027: Guideline for European Technical Approval of Falling Rock Protection Kits. Available online: https: / / www.eota.eu/sites/default/files/uploads/ETAGs/etag-027-april-2013.pdf (accessed on 3 November 2021).

12. Volkwein, A.; Gerber, W.; Klette, J.; Spescha, G. Review of Approval of Flexible Rockfall Protection Systems According to ETAG 027. Geosciences 2019, 9, 49. [CrossRef]

13. Toe, D.; Mentani, A.; Govoni, L.; Bourrier, F.; Gottardi, G.; Stéphane, L. Introducing Meta-models for a More Efficient Hazard Mitigation Strategy with Rockfall Protection Barriers. Rock Mech. Rock Eng. 2018, 51, 1097-1109. [CrossRef]

14. Nicot, F.; Cambou, B.; Mazzoleni, G. From a constitutive modelling of metallic rings to the design of rockfall restraining nets. Int. J. Numer. Anal. Methods Geomech. 2001, 25, 49-70. [CrossRef]

15. Volkwein, A. Numerical simulation of flexible rockfall protection systems. In Proceedings of the International Conference on Computing in Civil Engineering 2005, Cancun, Mexico, 12-15 July 2005; pp. 1-11.

16. Boulaud, R.; Douthe, C. A comparative assessment of ASM4 rockfall barrier modelling. Eng. Struct. 2022, 251, 113512. [CrossRef]

17. Hambleton, J.P.; Buzzi, O.; Giacomini, A.; Spadari, M.; Sloan, S.W. Perforation of flexible rockfall barriers by normal block impact. Rock Mech. Rock Eng. 2013, 46, 515-526. [CrossRef]

18. Coulibaly, J.; Chanut, M.; Lambert, S.; Nicot, F. Toward a Generic Computational Approach for Flexible Rockfall Barrier Modeling. Rock Mech. Rock Eng. 2019, 52, 4475-4496. [CrossRef]

19. Olmedo, I.; Chanut, MA.; Douthe, C.; Verdet, M.; Galandrin, C.; Dugelas, L.; Bertrand, D. Étude expérimentale multi-échelle sur les écrans pare-blocsomportement des ouvrages hors cadre ETAG27. Rev. Fr. Geotech. 2020, 163, 8. [CrossRef]

20. Boulaud, R.; Douthe, C.; Sab, K. Modelling of curtain effect in rockfall barrier with the dynamic relaxation. Int. J. Solids Struct. 2020, 200-201, 297-312. [CrossRef]

21. Les Collections de l'Ifsttar Méthodes d'Ausculatation de la Structure. Mesure de Forces. Mesure de la Tension des Câbles et Armatures de Précontrainte au Moyen de l'Arbalète Principe et Description Sommaire; Technical Report; Ifsttar: Champs-sur-Marne, France, 2015.

22. Day, A. An introduction to dynamic relaxation. Engineer 1965, 219, 218-221. 
23. Douthe, C.; Baverel, O. Design of nexorades or reciprocal frame systems with the dynamic relaxation method. Comput. Struct. 2009, 87, 1296-1307. [CrossRef]

24. Grassl, H.G. Experimentelle und Numerische Modellierung des Dynamischen Trag- und Verformungsverhaltens von Hochflexiblen Schutzsystemen Gegen Steinschlag. Ph.D. Thesis, ETH Zurich, Zurich, Switzerland, 2002. [CrossRef]

25. Coulibaly, J.; Chanut, M.A.; Lambert, S.; Nicot, F. Sliding cable modeling: An attempt at a unified formulation. Int. J. Solids Struct. 2018, 130, 1-10. [CrossRef]

26. Dugelas, L.; Coulibaly, J.; Bourrier, F.; Lambert, S.; Chanut, M.; Olmedo, I.; Nicot, F. Assessment of the predictive capabilities of discrete element models for flexible rockfall barriers. Int. J. Impact Eng. 2019, 133, 103365. [CrossRef] 